\title{
¿Meritocracia o Equidad? Concepciones de justicia social en fracciones trabajadoras de Argentina del siglo veintiuno ${ }^{1}$
}

Meritocracy or Equity? Conceptions of social justice in working classes in Argentina in the twenty first century

\author{
Edna Muleras \\ Facultad de Filosofia y Letras, Instituto de Investigaciones en Ciencias de la Educación (IICE), \\ Facultad de Ciencias Sociales, Instituto de Investigaciones Gino Germani \\ Universidad de Buenos Aires / CONICET, Argentina \\ emuleras@retina.ar
}

\section{Resumen:}

¿Es la igualación social un valor sustantivo en los trabajadores de las sociedades contemporáneas? ¿Es la inequidad social observada por quienes padecen sus efectos? ¿Cuál es el criterio de justicia social que prevalece en la evaluación de la propia situación de vida? ¿Un juicio retributivo meritocrático según el cual el bienestar o su carencia son atribuidos exclusivamente a la responsabilidad individual? ¿ $\mathrm{O}$ un juicio moral distributivo en el que se analizan como resultantes de un conjunto de restricciones impuestas por la desigualdad de condiciones, derechos y posibilidades de desarrollo entre las clases sociales? Se propone instalar la discusión a partir de diversas concepciones de justicia social relevadas empíricamente en una investigación exploratoria de tipo comparativo en algunas fracciones de trabajadores de Argentina entre los años 2010 y 2015. El estudio ofrece pistas valiosas para formular nuevas hipótesis sobre algunas de las precondiciones culturales de la instalación de nuevos gobiernos neoliberales en la región, a pesar de impulsar cambios estructurales que afectan los avances obtenidos en la igualación de derechos durante la primera década y media del siglo veintiuno.

Palabras Clave: Concepciones justicia social, Meritocracia, Equidad social, Trabajadores, Siglo veintiuno.

\begin{abstract}
:
Is social equity still a substantive value for working class in our contemporary societies? Is social inequality observed by those who suffer its consequences? Which is the conception of social justice that prevails when evaluating their own situation? A meritocratic conception according to which the situation is exclusively attributed to individual responsibility? Or a distributive conception that presents personal situation as restricted by unequal conditions, rights and development possibilities among social classes? Diverse conceptions of social justice were empirically surveyed in an exploratory and comparative research on working class moral identity, in Argentina in the last years (2010-2015). The study offers valuable clues to make newhypothesis about some of the cultural preconditions of the electoral success of the new neoliberal governments in the region, even though they drive structural changes which affect the extension of rights previously achieved by working class.
\end{abstract}

KEYWORDS: Social justice conceptions, Meritocracy, Social equity, Workers, Twenty first century.

\section{INTRODUCCIÓN: EL PROBLEMA Y LOS INTERROGANTES}

Estudios empíricos recientes evidencian una profundización creciente de la desigualdad de clase en las sociedades contemporáneas, a partir de la progresiva concentración del capital global en muy pocas manos ${ }^{2}$. América Latina -si bien ha experimentado una reducción de la desigualdad durante la primera década del siglo veintiuno, gracias a la confluencia de crecimiento económico, políticas redistributivas y voluntad política de cambio- continúa siendo la región más desigual del planeta (Informe CEPAL, 2009) ${ }^{3}$. En el caso particular de Argentina, en sucesivos períodos de los últimos cincuenta años, la clase trabajadora en su conjunto fue severamente afectada en sus condiciones sociales de vida por las políticas neoliberales aplicadas en una nueva etapa de expansión capitalista en la región. Primero, durante la última dictadura cívico militar (1976-1983), y posteriormente, en la década del noventa, durante los gobiernos constitucionales de Carlos 
Saúl Menem (1989 - 1999) y Fernando de la Rúa (1999-2001), que derivaron en una profunda crisis social en el año 2001. A partir de 1976 se instala una estructura distributiva claramente regresiva en la que se observa-con algunas oscilaciones-una tendencia progresiva a la disminución de la participación de los asalariados en la distribución del PBI. Dicha tendencia registra sus menores niveles históricos durante la última dictadura, la crisis hiperinflacionaria de los ochenta y hacia mediados de los noventa, lo cual termina por desatar una profunda crisis social en el año 2001 (Figura ${ }^{\circ} 1$ ).

FIGURA No 1

Participación de los asalariados en el PBI (a precios corrientes). Argentina 1935- 2005.

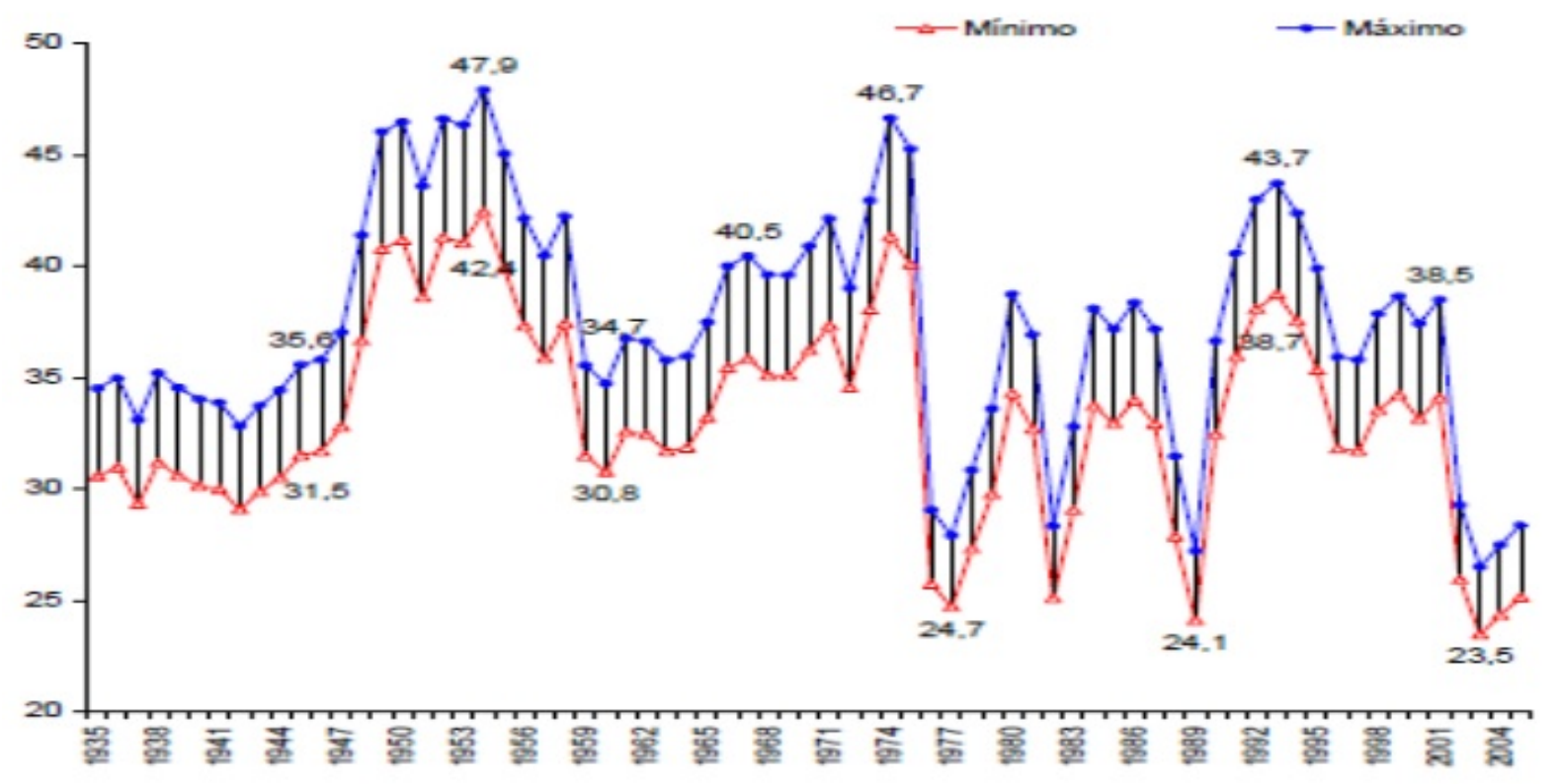

Fuente: CIFRA N9/ CTA /2011/ Graña 2007/pag.7.

Esta tendencia negativa comienza a revertirse-aunque sin llegar a retomar los valores de 1974/1975a partir de las políticas redistributivas implementadas por los gobiernos de Néstor Kirchner (2003-2007) y Cristina Fernández de Kirchner (2007-2015) en el nuevo milenio. Con el estímulo a una política industrial orientada fundamentalmente al desarrollo del mercado interno, se favorece un descenso sostenido de la desocupación y el trabajo no registrado o informal, por lo que se puede observar una considerable recuperación de la participación de los asalariados en la distribución del PBI (Figura n ${ }^{\circ} 2$ ) y una disminución de la desigualdad social medida por el coeficiente de Gini (Figura ${ }^{\circ} 3$ ), en relación con los valores asumidos por dichos indicadores a partir de la crisis del 2001.Sin embargo, este ciclo progresivamente favorable para los trabajadores se interrumpe nuevamente a partir de diciembre del año 2015 con la asunción del actual gobierno, que implicó un drástico cambio en la orientación de la política económica. 
FIGURA $\mathrm{N}^{\mathrm{T}} 2$

Participación de los asalariados en el PBI. Argentina 2003-2016

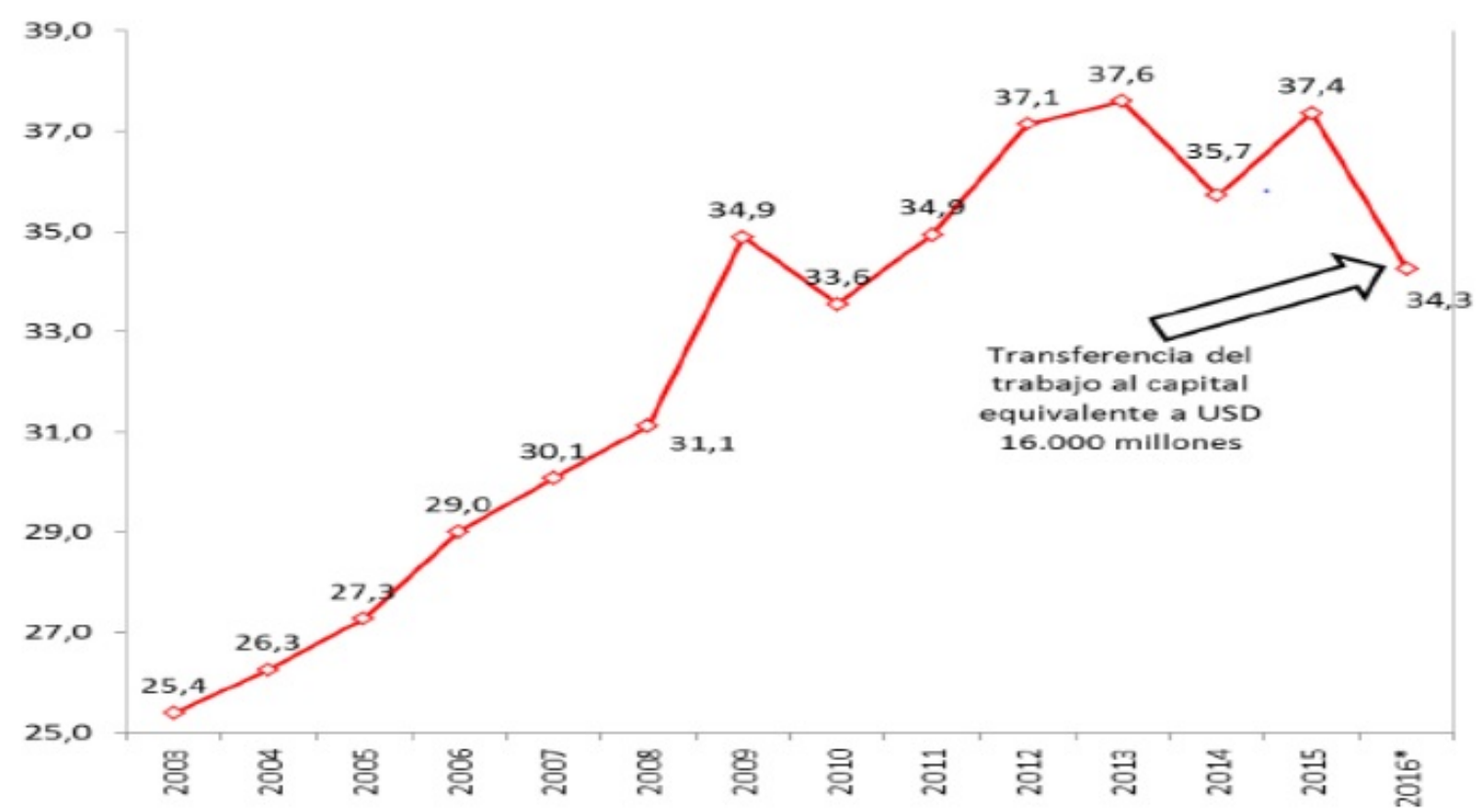

Fuente: CIFRA MAYO 2017/CTA/ARGENTINA

FIGURA $N^{\circ} 3$

Evolución coeficiente de Gini por ingreso de la ocupación principal. Período 1974- 2010.

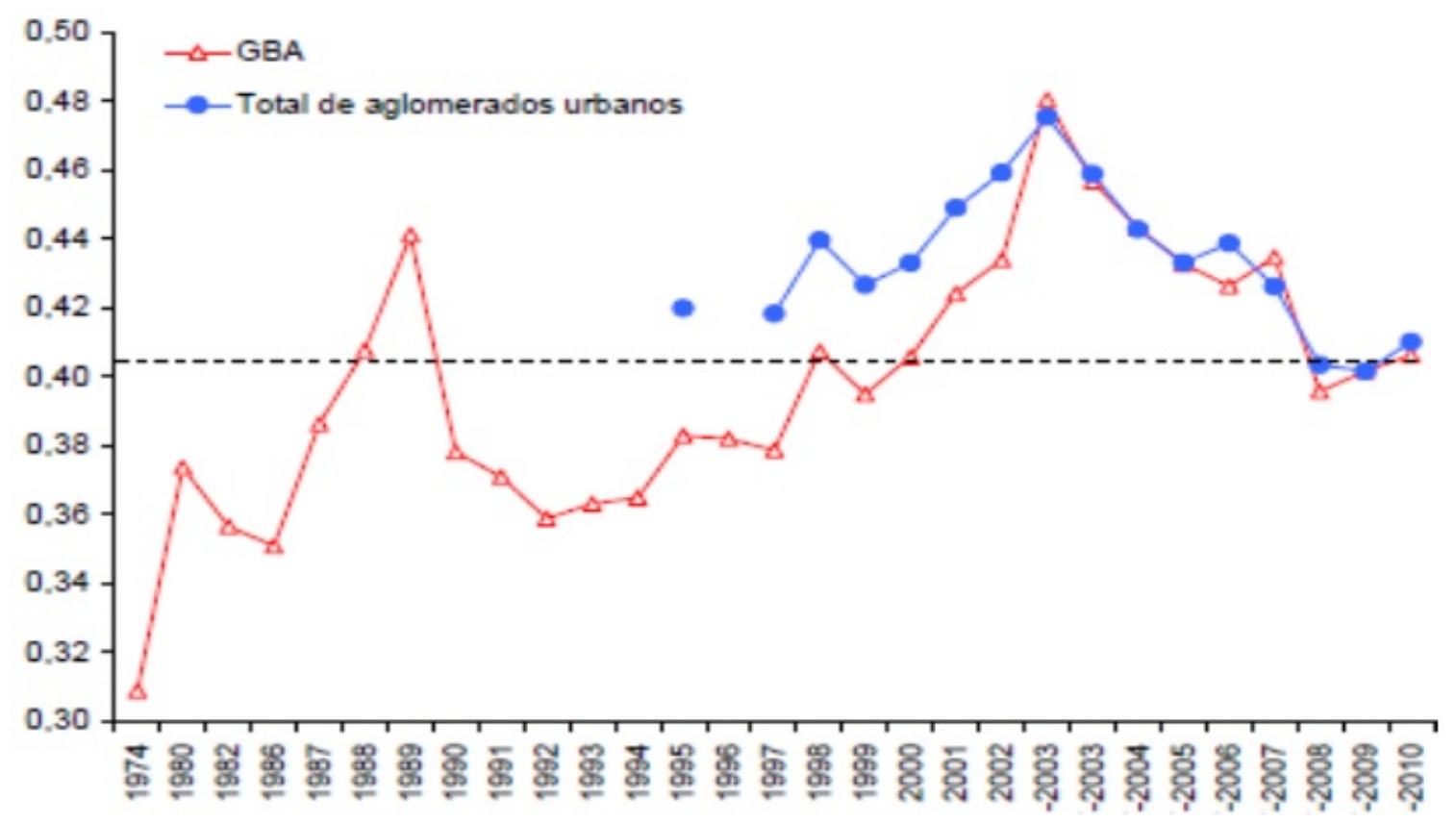

Fuente: CIFRA N ${ }^{\circ}$ /CTA/ 2011/Argentina/ p.13

Con base en un conjunto de datos recientes se podría plantear, como hipótesis de trabajo, una profundización en curso de la desigualdad de clase ( $\operatorname{Tabla~}^{\circ} 1$ y Tabla $\mathrm{n}^{\circ} 2$ ). Esto origina varios interrogantes sobre el grado de conciencia de los trabajadores sobre el conjunto de procesos en marcha, es decir, sobre 
las precondiciones objetivas de las que disponen para enfrentarla creciente amenaza a sus chances de reproducción social.

TABLA No 1

Evolución de indicadores socioeconómicos Argentina 2016-2017

\begin{tabular}{|c|c|}
\hline INDICADORES SOCIOECONOMICOS & FUENTE \\
\hline$\uparrow \uparrow$ Desigualdad según coeficiente de Gini & EPH/ INDEC/Argentina: Evolución 2015-2017/ Mayo 2017) \\
\hline 个个 Tasa de desempleo & (EPH/ INDEC/Argentina: Evolución 2015-2017/ Mayo 2017) \\
\hline 个个 Tasa de desempleo & CIFRA / CTA Argentina Informe 2017 \\
\hline$\downarrow \downarrow$ Empleo formal o registrado & CIFRA / CTA Argentina Informe 2017 \\
\hline$\downarrow \downarrow$ Salario real de trabajadores con bajos ingresos & $\begin{array}{l}\text { Centro de Estudios de la Ciudad CEC/ Facultad Ciencias Sociales/ } \\
\text { Universidad de Buenos Aires } 2017\end{array}$ \\
\hline $\begin{array}{l}\uparrow \uparrow \text { Especulación financiera, deuda externa y fuga de } \\
\text { capitales }\end{array}$ & $\begin{array}{l}\text { Basualdo y Manzanelli, 2017, Buenos Aires; } \\
\text { https:// www. Pagina12.com.ar/ 55334- endeudar-y-fugar }\end{array}$ \\
\hline
\end{tabular}

TABLA No 2

Efectos en el tejido social de la evolución de indicadores socioeconómicos Argentina 2016-2017

\begin{tabular}{|c|c|}
\hline INDICADORES SOCIOECONOMICOS & FUENTE \\
\hline$\uparrow \uparrow$ Pobreza infantil & UNICEF Argentina: 2017 \\
\hline$\downarrow \downarrow$ Decrecimiento en el consumo de leche & $\begin{array}{l}\text { Subsecretaría de Lechería del Ministerio de Agroindustria de la } \\
\text { Nación, Argentina, } 2017\end{array}$ \\
\hline $\begin{array}{l}\uparrow \uparrow \text { Mortalidad infantil en la Ciudad de Buenos } \\
\text { Aires }\end{array}$ & $\begin{array}{l}\text { UNICEF Argentina: 2017, Informe Fundación Soberanía Sanitaria en } \\
\text { https:// ww.pagina12.com.ar/50640-el-terrible-costo-del-recorte }\end{array}$ \\
\hline
\end{tabular}

Este problema -el del proceso de conocimiento del orden social en distintas fracciones de la clase obrera en Argentina en la última década-es el objeto de estudio de la investigación exploratoria que llevamos adelante $^{4}$. Desde un enfoque integrador del carácter biológico, mental y social del campo de acción y pensamiento de los grupos humanos, investigamos la interrelación de factores socioculturales y psicogenéticos operantes en la configuración de la diversidad de los contenidos de significación, de las estructuras, lógicas de la reflexión, y del juicio moral con los cuales los trabajadores describen, explican y evalúan los procesos que afectan sus propias condiciones sociales de vida. En la etapa actual de nuestro trabajo procuramos identificar los factores constituyentes de la diversidad de representaciones de la estructura social, así como de las explicaciones atribuidas a su funcionamiento sistémico. Asimismo, se analizan los factores que configuran las concepciones de justicia social con las que evalúan la propia situación en general, teniendo en consideración la evolución de la desigualdad de clase en la sociedad 
argentina en las últimas décadas. Indagamos en qué medida una mejora o empeoramiento relativo en las condiciones sociales de vida de la clase trabajadora se corresponde o no con un avance en el plano del conocimiento. Centralmente, nos preguntamos:

1. ¿Es la inequidad social observada/ conocida por quienes padecen sus efectos?¿Cómo describe y explica la clase trabajadora la estructura y funcionamiento del orden social?

2. ¿Es la desigualdad de clase cuestionada desde el punto de vista moral? ¿Cuál es el criterio de justicia social que prevalece en los trabajadores a la hora de evaluar la propia situación de vida? ¿Expresan una moral retributiva meritocrática (Piaget, 1984, pp. 169- 220; Rosanvallon, 2012, pp. 115-120), según la cual el bienestar o su carencia se atribuyen exclusivamente a la responsabilidad individual? ¿O es juzgada a partir de una moral distributiva (Piaget, 1984, pp. 220-262; Rosanvallon, 2012, pp. 280-286), como el producto resultante de un conjunto de restricciones impuestas por sustantivas diferencias en las condiciones y posibilidades de desarrollo entre las clases sociales?

3. ¿Mantiene su vigencia en la clase trabajadora del siglo veintiuno el ideario revolucionario democrático de una soberanía popular originada en la construcción de una sociedad equitativa respecto de la distribución de recursos materiales y simbólicos? ${ }^{5}$

Consideramos que los resultados preliminares de nuestro estudio ofrecen claves valiosas para identificar procesos observables (Piaget, 1985, pp. 265-274; Piaget y García, 1989), obstáculos epistemológicos (Bachelard, 1987, p. 15) y aspectos inobservados sobre el conocimiento del orden social por las fracciones trabajadoras estudiadas, así como también factores que propician su construcción.

Entre otros hallazgos, se registra a nivel empírico el predominio de una concepción de justicia retributiva meritocrática, en la que prima una noción de responsabilidad individual. Esta concepción de justicia social no sólo opera como criterio de justificación moral de la adversidad padecida en la propia situación de vida, sino que se constituye en obstáculo epistemológico para la captación del origen objetivo de su padecimiento. En este sentido, los resultados preliminares del estudio contribuyen, en primer lugar, a la formulación de algunas hipótesis interpretativas sobre algunos de los factores que pueden vincularse a la aceptación y justificación moral de las políticas actualmente en curso, a pesar de que las mismas produzcan objetivamente un deterioro progresivo en las condiciones sociales de vida de las fracciones trabajadoras. Dicho de otro modo, permiten visualizar algunas de las precondiciones culturales de la instalación de nuevos gobiernos neoliberales en la región, a pesar de impulsar cambios estructurales que afectan los avances obtenidos en la igualación de derechos durante la primera década y media del siglo veintiuno.

En segundo lugar, los datos obtenidos nos permiten fundamentar empíricamente una hipótesis orientativa del estudio en curso, en relación a las precondiciones del avance del conocimiento del orden social. Los hechos registrados dan cuenta del papel clave desempeñado por el proceso de descentración en el doble plano lógico y moral (Piaget, 1986a, pp. 76, 78; 1972, pp. 101, 163, 210). Nos referimos al proceso estudiado en profundidad en las investigaciones experimentales psico y sociogenéticas de la Escuela de Epistemología Genética de Jean Piaget. La localización empírica de algunos de sus modos concretos de manifestación en la clase trabajadora de la Argentina contemporánea remarca la importancia de investigar tanto las etapas primarias de su desenvolvimiento como los factores que contribuyen a su realización efectiva.

\section{Metodología}

Llevamos adelante un estudio exploratorio comparativo de casos, a partir de la selección de universos empíricos de trabajadores diferenciados en el plano de su identidad epistémica por las etapas/ grados de desarrollo de su conocimiento del orden social. Durante la última década abordamos dos universos empíricos concretos. En tanto el primer universo apela a la intervención de un orden divino, trascendente a lo humano, para protegerse y/o transformar una situación de vida desfavorable, el segundo recurre a las armas profanas de la lucha colectiva. 
El primero corresponde a un universo de trabajadores creyentes -los devotos de San Cayetano, el santo de los trabajadores en Argentina- que expresan una concepción sacralizada del mundo, propia de las etapas primarias del conocimiento de lo social. Efectuamos en total cinco relevamientos en terreno durante dos décadas: tres durante los noventa del siglo veinte, y dos en la primera década del siglo veintiuno; el último corresponde al año 2010 (Muleras, 2013, 2012, 2011, 2010, 2009, 2008).

El segundo universo corresponde al de los trabajadores de la industria de procesamiento de pescado de la ciudad de Mar del Plata, principal centro industrial pesquero del país. (Muleras, Schulze, Muñiz, y Azcarate, 2018; Muleras et al., 2016, Muleras, Damiano, y Hernández, 2014; Muleras, 2015a y b). La depredación del recurso pesquero provocado por la creciente concentración monopólica nacional e internacional de la industria en las últimas décadas origina períodos prolongados de inactividad y altos índices de desempleo en esta rama de la actividad (Atucha; López, y Volpato,1997; Gennero de Rearte, Graña y Liseras, 2009), lo que produce numerosos conflictos y luchas para enfrentar la amenaza de desocupación y el deterioro de las condiciones de trabajo entre los años 1997 y 2007 (Colombo, 2009; Colombo et al., 2010; Nieto, 2012, 2010).

Nuestro equipo de investigación realizó un total de 161 entrevistas durante diciembre de 2014 y julio de $2015^{6}$, en una muestra no probabilística, intencional por cuotas de trabajadores diferenciados por tamaño de la empresa y tipo de vínculo laboral formal o informal (sociedades anónimas o "seudocooperativas"), ocupación concreta en la línea de producción y sexo (Tabla n³).

TABLA No 3

Cuotas de entrevistados en empresas industriales de procesamiento de pescado de la ciudad de Mar del Plata

\begin{tabular}{|l|l|l|l|l|l|}
\hline $\begin{array}{l}\text { SEXO Y TAMAÑO DE LA EMPRESA } \\
\text { OCUPACION }\end{array}$ & $V+50$ & $V-50$ & $\mathbf{M}+\mathbf{5 0}$ & $\mathbf{M}-\mathbf{5 0}$ & TOTAL \\
\hline FILETEROS & 20 & 26 & 5 & 8 & $\mathbf{5 9}$ \\
\hline EMPACADORES & 2 & & 31 & 18 & $\mathbf{5 1}$ \\
\hline PEONES & 16 & 13 & 6 & 7 & 42 \\
\hline EMPLEADOS DE LIMPIEZA Y OTRAS & 3 & 1 & 2 & 3 & 9 \\
\hline TOTAL & $\mathbf{4 1}$ & $\mathbf{4 0}$ & $\mathbf{4 4}$ & $\mathbf{3 6}$ & $\mathbf{1 6 1}$ \\
\hline
\end{tabular}

Fuente: Relevamiento propio en empresas (Solimeno, Argentina Frozen Fish, Angelito, Cabo Asturia, Cadelafi, Mardi). Diciembre 2014 y Julio 2015.

Se aplica en terreno un modelo de entrevista combinada, estructurada con preguntas de respuestas abiertas (típicas de las entrevistas clínicas y las entrevistas en profundidad)y con preguntas de respuestas precodificadas (típicas de las encuestas) de una hora de duración aproximada. Se orienta al desencadenamiento y captación empírica de una serie de reflexiones, creencias, juicios morales, evaluaciones, apreciaciones y razonamientos verbalizados por los entrevistados, en las distintas dimensiones analíticas de interés. Asimismo, se indaga su correspondencia con un conjunto de dimensiones demográficas, económicas, ocupacionales, educativas, culturales y afectivo-emocionales, de modo tal de hacer plausible la identificación 
de factores asociados y/o explicativos de la diversidad de juicios morales sobre la justicia social y la diversidad representativa del orden social.

La presencia cuantitativamente significativa de preguntas abiertas que operan como estímulos desencadenantes de reflexiones y juicios morales permite captar con mayor profundidad -aun dentro de los límites de la técnica de registro empleada en un universo cuantitativamente extenso- las significaciones que los sujetos atribuyen a sus acciones y pensamientos.

A los fines de captar los juicios morales de evaluación de la propia situación social de vida se plantean los siguientes interrogantes:

\section{5. ¿Ud. está conforme con su situación actual (en general, su situación de vida)?

Los datos presentados en el próximo apartado surgen del procesamiento de las respuestas a dichas preguntas.

\section{Resultados}

Toda moral implica un sistema de normas y valores compartidos, necesarios para la convivencia humana, un ethos orientativo de la conducta. La norma de justicia es un regulador clave en la interrelación social. En tal sentido el orden normativo y el orden social son dos caras de una misma moneda, tal cual plantea Durkheim $(1993,1985)$. Sin embargo, Piaget advierte en esa formulación una distorsión: el orden normativo constituyente es producido e instalado por los grupos humanos que ejercen un dominio en el orden social, y no por la sociedad en su conjunto, tal como propone Durkheim. En la práctica, produce ciertos comportamientos e inhibe otros. A nivel de la conciencia, la evaluación de una situación como "justa" o "injusta" incide en su aceptación o cuestionamiento, en su reproducción o crisis. Sin embargo, el principio de justicia puede asumir significaciones muy diversas.

En las investigaciones experimentales piagetianas de la década del treinta sobre la génesis y evolución de la identidad moral (1984) se encuentra que la concepción de la justicia varía sustancialmente en las distintas etapas del desarrollo psicogenético, guardando analogías con su evolución histórica en las formaciones sociales. Con base en sus aportes, es posible distinguir dos nociones principales. La más primaria es la de justicia retributiva, en la cual se concibe necesaria la génesis y preservación del orden normativo a través de relaciones sociales de autoridad. Las normas regulatorias del comportamiento social se instauran en relaciones sociales asimétricas en las que se confiere a la autoridad la legitimidad del control, evaluación y sanción permanente del comportamiento. El propósito principal de la justicia retributiva es instrumental: reproducir o inhibir comportamientos aceptados o no aceptados socialmente. De este modo, se considera necesario castigar la ruptura normativa, es decir, la ruptura de la relación social de autoridad -la falta-y premiar el comportamiento adecuado al orden normativo: el mérito. 
En relación con esta lógica, los acontecimientos favorables o adversos de la vida pueden ser concebidos como una expresión inmanente (Piaget, 1984, p.211) -necesaria, automática, universal e ineludible- de realización de una retribución/ sanción del propio comportamiento. En la identidad del individuo favorecido o desfavorecido se infiere necesariamente un comportamiento virtuoso o incorrecto. Expresiones tales como "se lo merece", "por algo será" y "algo habrá hecho "ilustran con nitidez la creencia en una justicia retributiva inmanente, que inexorablemente se realiza más temprano que tarde. Se trata de una cosmovisión antropocéntrica, teleológica y finalista, excluyente de las nociones de azar y teleonomía (Monod, 2000, p.20).

La concepción de una justicia distributiva se origina en una moral de equidad y autonomía que surge de la crisis, confrontación y reestructuración de la moral de autoridad y heteronomía que prevalece en las etapas anteriores. En ella, el valor fundamental a preservar no es el de la sanción permanente del comportamiento -la retribución positiva o negativa, como premio o como castigo-, sino la paridad o igualación humana, la distribución equitativa de recursos materiales y simbólicos, derechos y posibilidades de desarrollo, con respeto a las necesidades y potencialidades particulares. Corresponde a la conciencia moral de una práctica social cooperativa, estructurada por relaciones sociales de un nuevo carácter de reciprocidad, respeto mutuo y solidaridad entre pares. Considera quela preservación del orden social no depende de un principio jerárquico de imposición normativa, sino, por el contrario, de una construcción democrática: la soberanía popular de los iguales. La cooperación implica necesariamente intercambio y discusión sobre diversos puntos de vista y cursos de acción posibles, a los fines de establecer autonómica y democráticamente las normas y los procedimientos de regulación de la vida social.

Ahora bien, ¿cuál es la concepción de justicia social prevaleciente en los trabajadores entrevistados? A continuación presentamos los datos obtenidos en el relevamiento.

Se registra en los trabajadores entrevistados tanto una mayoritaria declaración de conformidad (62\%) como de merecimiento (59\%), y resulta destacable la fuerte relación de correspondencia entre ambos indicadores. En quienes se declaran conformes, prácticamente se duplica la consideración de la propia situación de vida como "merecida" respecto a los disconformes (71\% vs. 38\%). Es plausible pensar que la concepción meritocrática se asocia a sentimientos positivos de aceptación de la propia situación, en tanto el juicio moral negativo aumenta considerablemente cuando se experimentan sentimientos de rechazo, al menos en algún grado. Así, tres cuartas partes de los que afirman merecer su situación se declaran conformes con ella; en cambio, en quienes niegan el merecimiento prevalecen los disconformes. Solamente un cuarto del total de entrevistados se declaran disconformes y niegan merecer su situación de vida (Figura $n^{\circ} 4$ y Figura $\left.n^{\circ} 5\right)$. 
FIGURA No 4

Juicio moral sobre la propia situación de vida en general por conformidad o disconformidad con ella

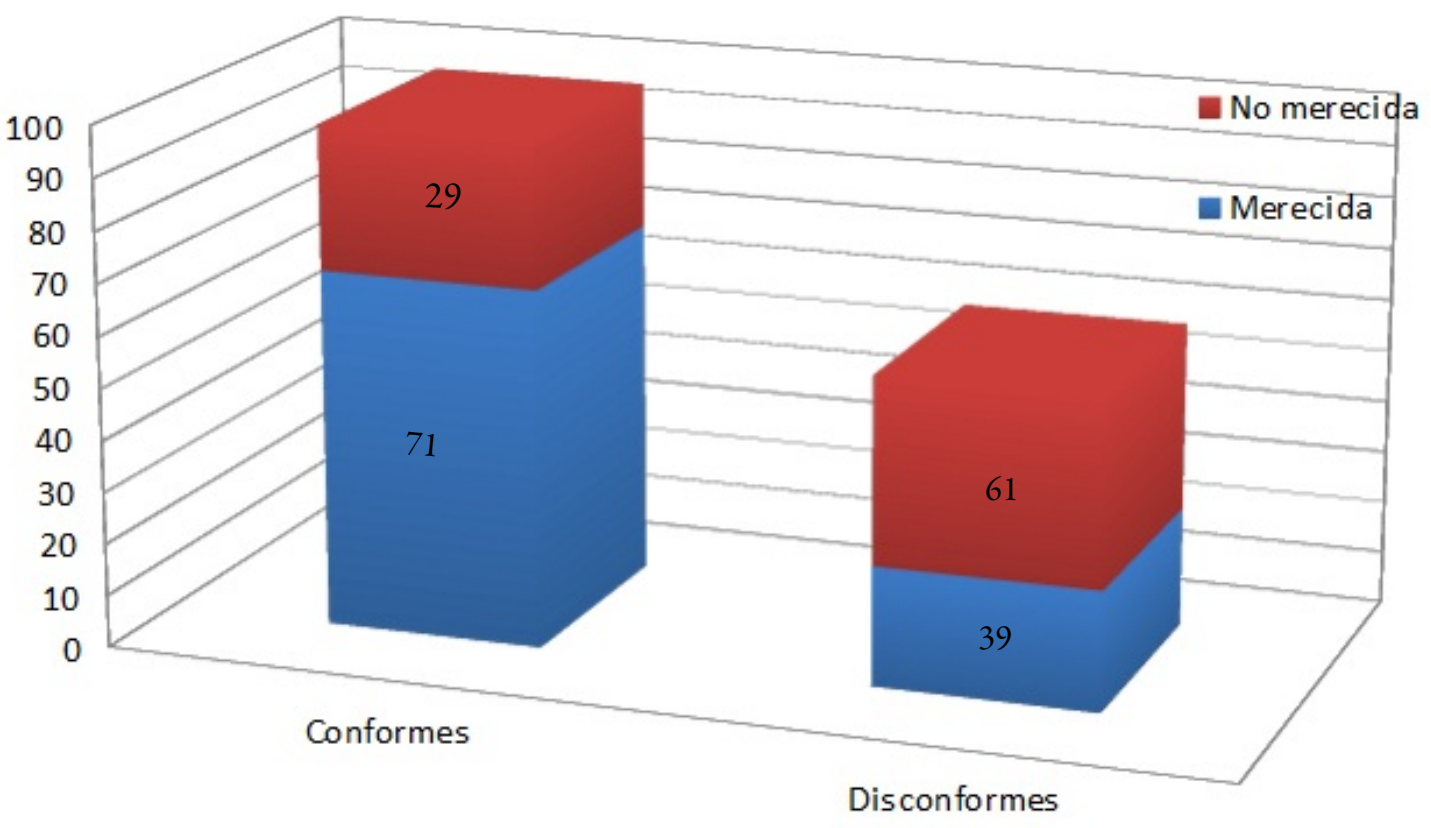

Fuente: Relevamiento propio en empresas (Solimeno, Argentina Frozen Fish, Angelito, Cabo Asturia,Cadelafi, Mardi). Diciembre 2014 y Julio 2015.

FIGURA No 5

Conformidad o disconformidad con la propia situación de vida en general por juicio moral sobre ella

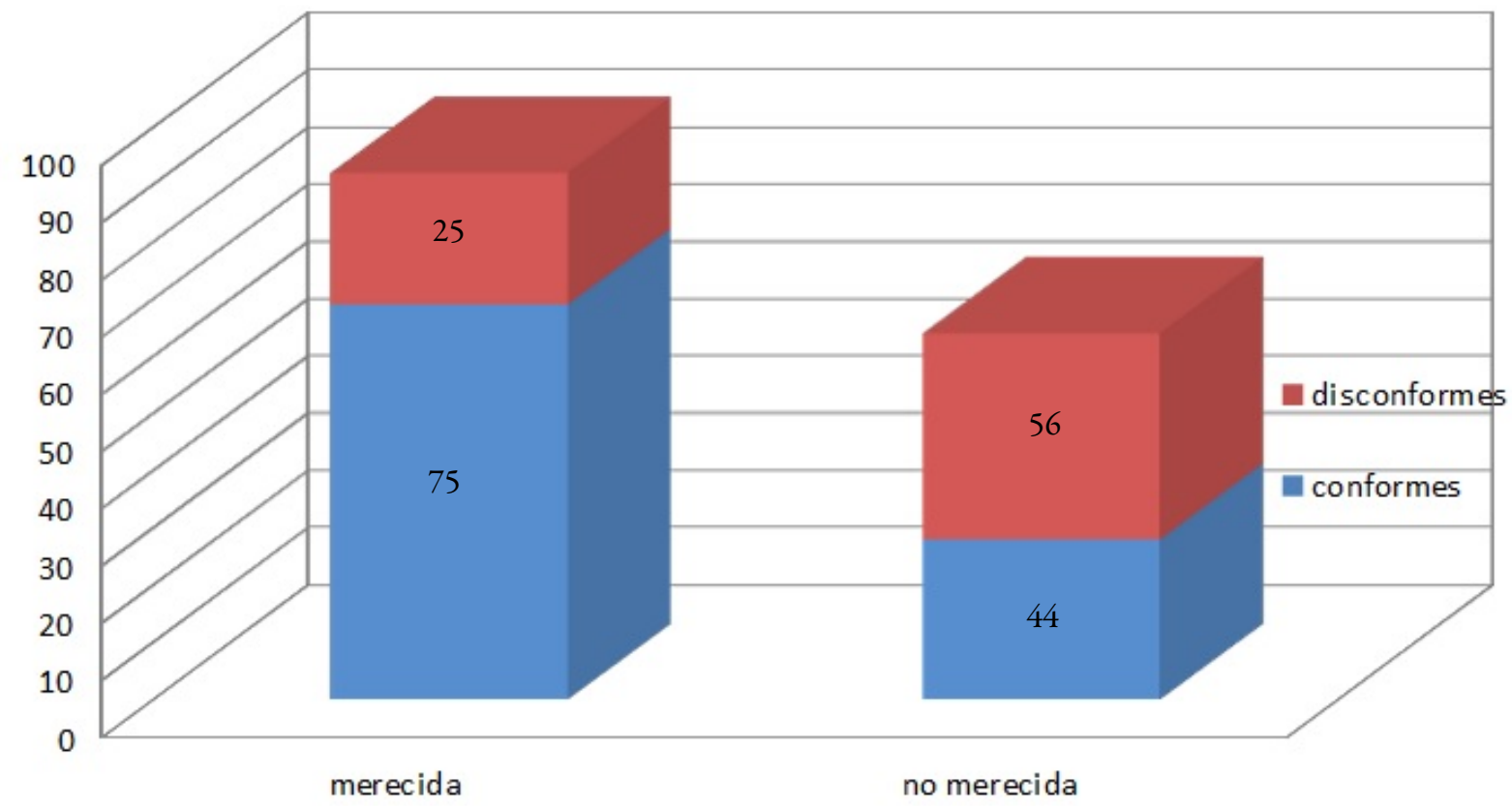

Fuente: Relevamiento propio en empresas (Solimeno, Argentina Frozen

Fish, Angelito, Cabo Asturia, Cadelafi, Mardi). Diciembre 2014 y Julio 2015.

Ahora bien, ¿qué quiere decir "merecido" o "no merecido"? ¿Cuál es la significación atribuida por los entrevistados a lo "merecido" o "no merecido"? Las respuestas a la pregunta abierta "¿Por qué lo considera merecido/ no merecido?" dan la clave. 
La diversidad de juicios morales sobre la justicia o injusticia de la propia situación de vida se asocia al tipo de identidad a la que se atribuye responsabilidad por la misma. La concepción de justicia social predominante es la retributiva meritocrática de responsabilidad individual. Involucra al 54,4\% de los entrevistados. En ella, se evalúa el bienestar o adversidad de la propia situación como expresión inmanente de una retribución positiva o negativa a virtudes individuales, al buen o mal comportamiento del sujeto. La acción individual implícitamente asume un carácter instrumental: se trata de un intercambio de equivalentes en el que se considera que el comportamiento individual virtuoso es condición moral para recibir ${ }^{7}$. Se concibe lo retribuido como proporcional a lo realizado. El comportamiento individual es pensado como el producto de la voluntad, decisión e intención estrictamente personales, independientes de factores contextuales y circunstanciales $^{8}$. La atribución de responsabilidad a sí mismos puede también articularse a la de un orden trascendente a lo humano - una justicia divina- que retribuye positiva o negativamente, más tarde o más temprano, el buen o mal comportamiento individual.

Sin embargo, es sustantivo el registro de concepciones de justicia social cualitativamente diferentes: prácticamente un tercio de los entrevistados evalúa su situación social de vida como "no merecida". Observan que la justa retribución no se produce, y atribuyen la responsabilidad por su situación de vida a nuevas identidades y factores. Es posible diferenciar dos grupos. El primero (16,9\%) observa la inexistencia de retribución, la falta de equivalencia entre el buen comportamiento individual y la magnitud o calidad de lo que recibe a cambio ${ }^{9}$. El segundo(17,5\%), además, hace presente una nueva identidad, inobservada por quienes adscriben sin dudar a la lógica meritocrática de responsabilidad individual: remarcan la responsabilidad de los factores sociales en la restricción de los márgenes de acción individual ${ }^{10}$ (Figura $\mathrm{n}^{\circ} 6$ ).

FIGURA No 6

Juicio moral sobre la propia situación de vida por identidad considerada responsable

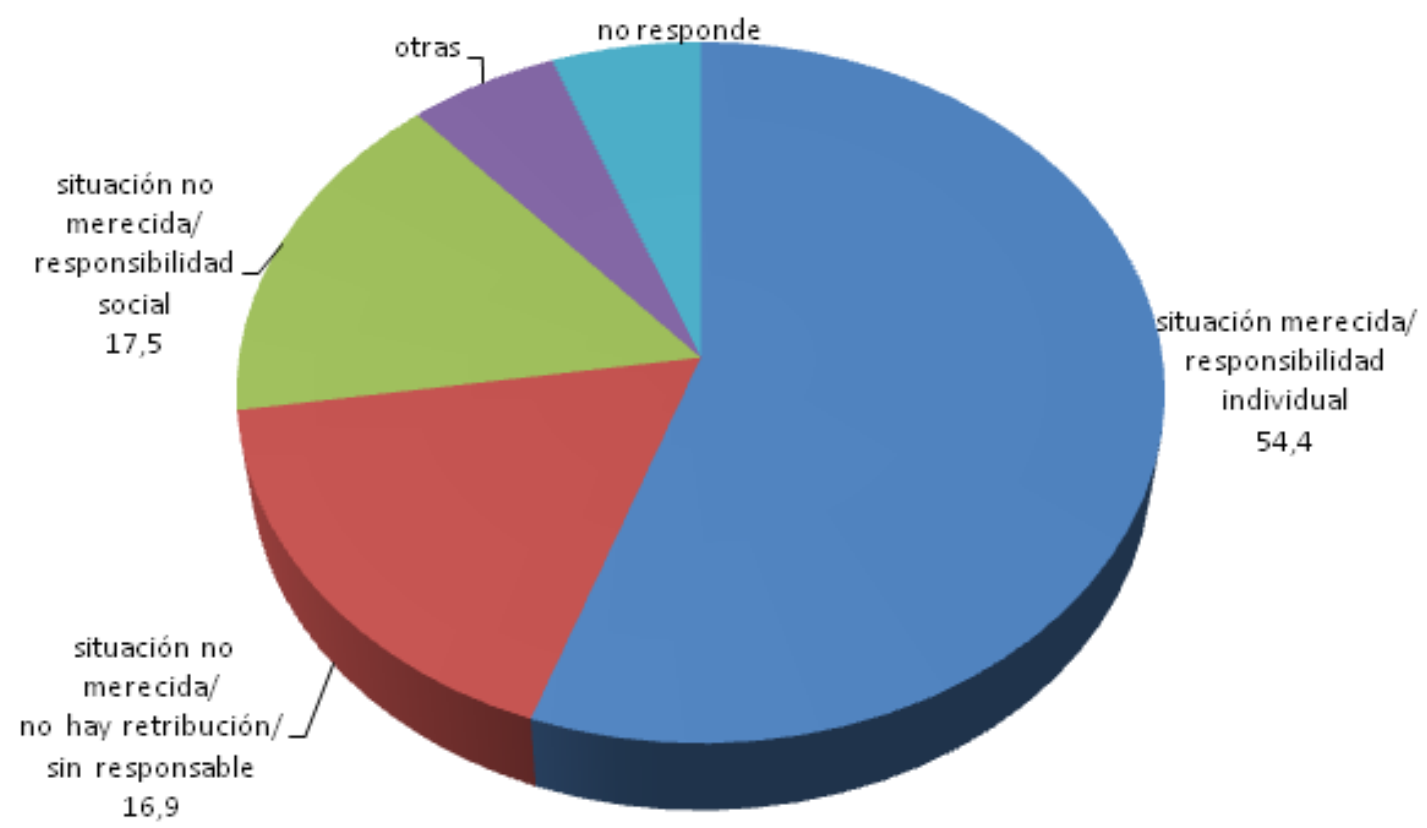

Fuente: Relevamiento propio en empresas (Solimeno, Argentina Frozen Fish, Angelito, Cabo Asturia, Cadelafi, Mardi). Diciembre 2014 y Julio 2015. 
Es significativo el predominio de juicios meritocráticos en los entrevistados que enfatizan la responsabilidad individual, y el predominio de juicios negativos en los entrevistados que enfatizan la responsabilidad social (Figura ${ }^{\circ} 7$ y Figura n $^{\circ} 8$ ).

\section{FIGURA $\mathrm{N}^{\circ} 7$}

Juicio moral sobre la propia situación de vida por tipo de identidad considerada responsable

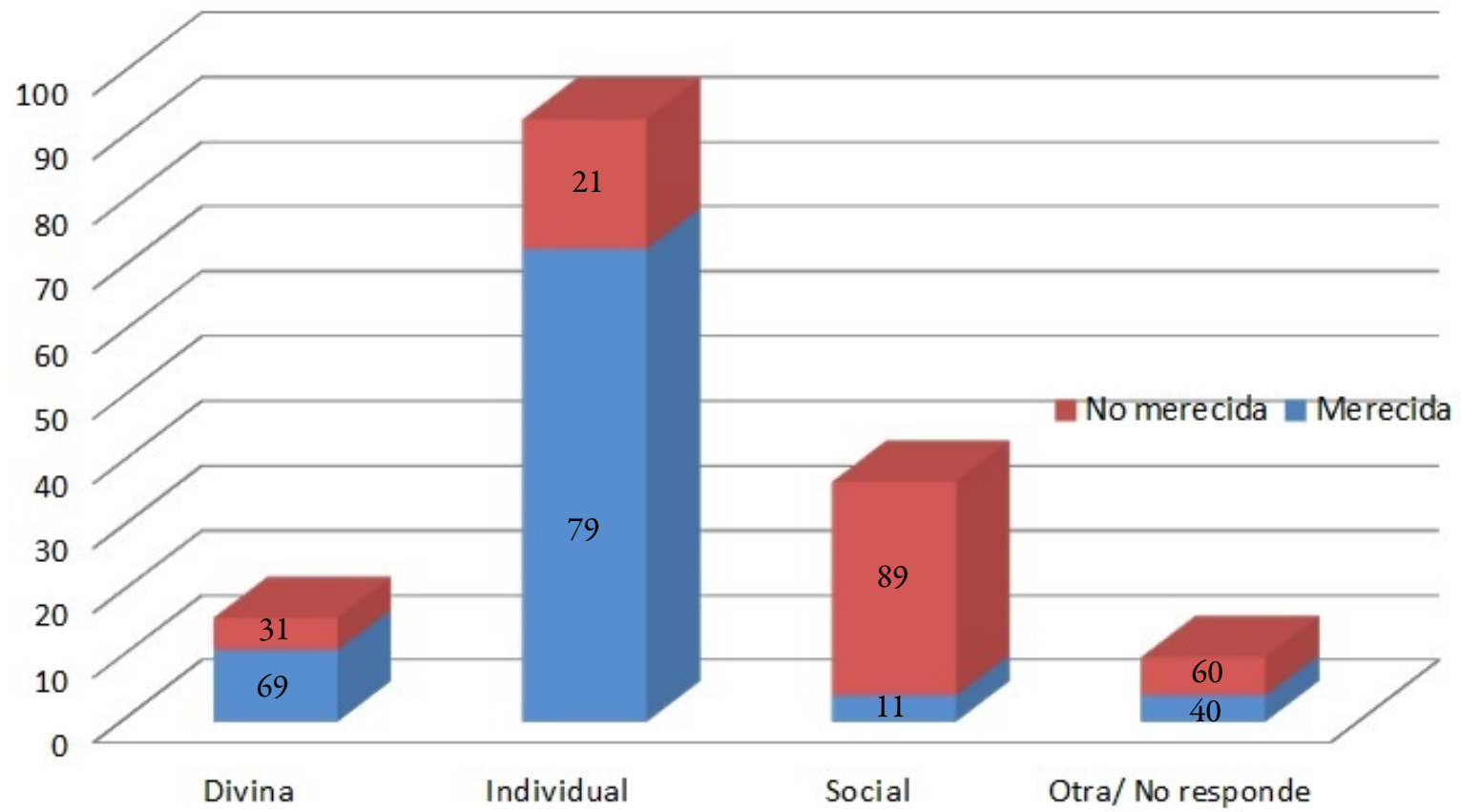

Fuente: Relevamiento propio en empresas (Solimeno, Argentina Frozen

Fish, Angelito, Cabo Asturia, Cadelafi, Mardi). Diciembre 2014 y Julio 2015

FIGURA $\mathrm{N}^{\circ} 8$

Tipo de identidad considerada responsable por juicio moral sobre la propia situación de vida

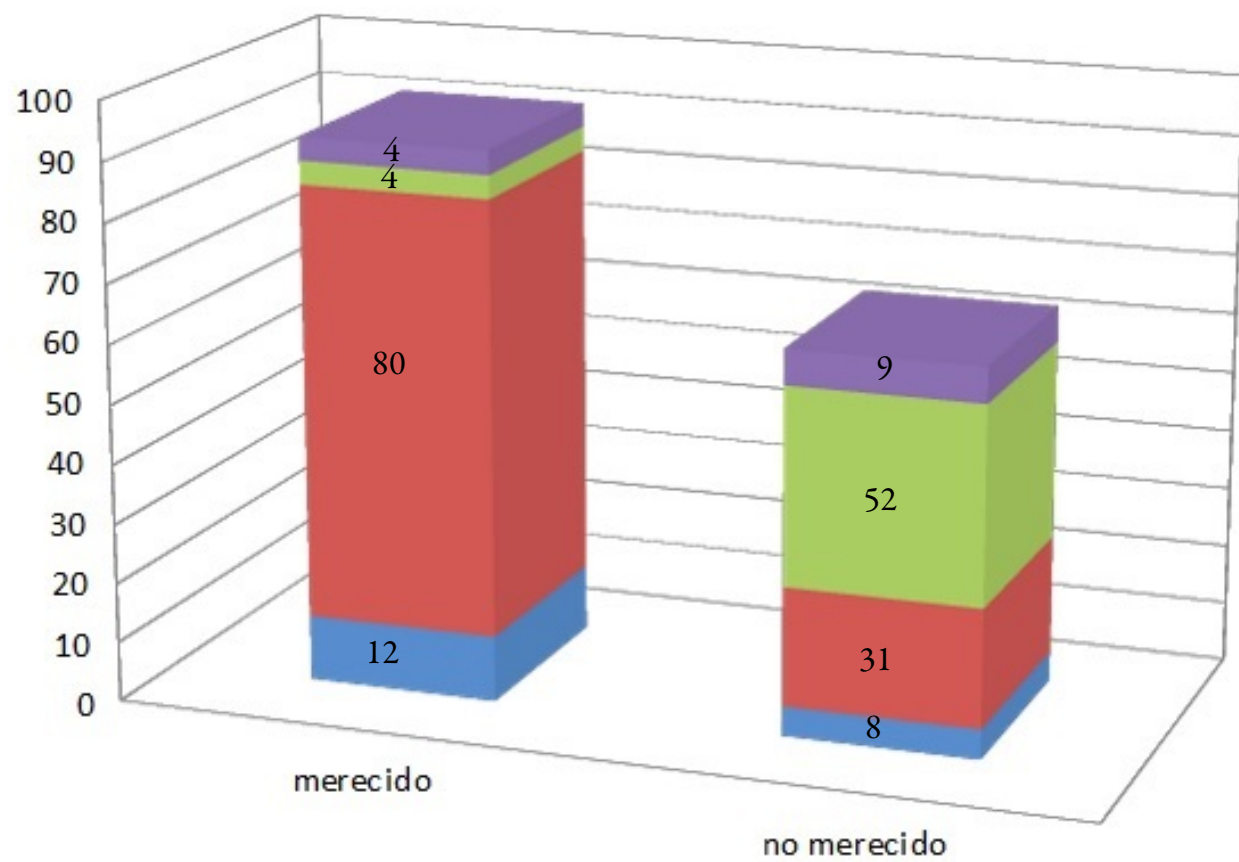

ns/otras

social

individual

divina

Fuente: Relevamiento propio en empresas (Solimeno, Argentina Frozen Fish, Angelito, Cabo Asturia, Cadelafi, Mardi). Diciembre 2014 y Julio 2015 
Pero lo que resulta más interesante aún es el predominio de la concepción meritocrática de justicia social en otros universos sociales, como el delos trabajadores devotos de San Cayetano (del área metropolitana de Buenos Aires), así como en universos sociales de sectores medios, como el de los estudiantes universitarios de la UBA, entrevistados en años anteriores y posteriores en el marco del estudio comparativo en curso (Figura $\mathrm{n}^{\circ} 9$ ). Si bien cabe mencionar que hay variaciones leves en función de la identidad social y cultural del universo de referencia, la conciencia moral dominante sobre la justicia social, en todos los universos abordados, es la retributiva meritocrática de responsabilidad individual ${ }^{11}$.

\section{FIGURA No9}

Juicio moral sobre la propia situación de vida por tipo de identidad considerada responsable en diferentes universos sociales

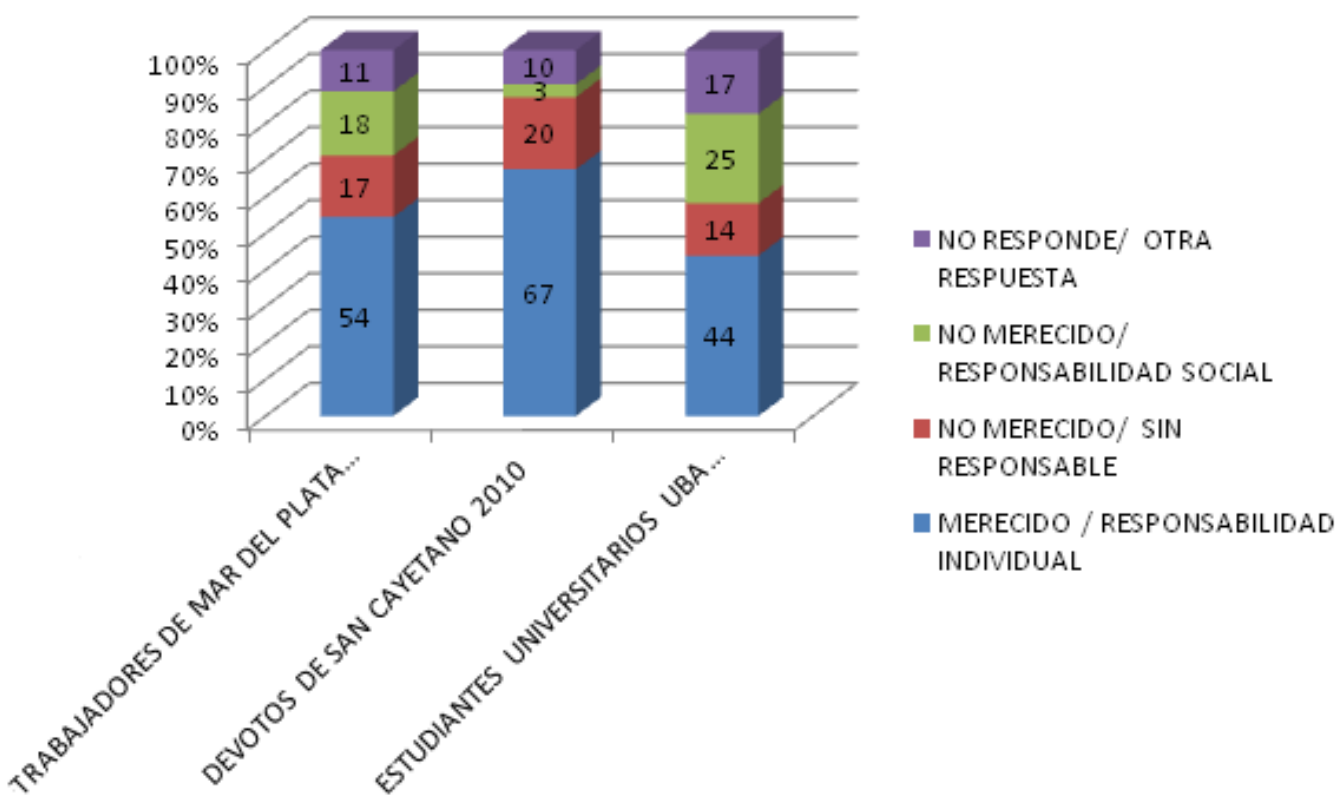

Fuente: Relevamiento propio en empresas (Solimeno, Argentina Frozen Fish, Angelito, Cabo Asturia, Cadelafi, Mardi). Diciembre 2014 y Julio 2015

En síntesis, los trabajadores entrevistados en terreno expresan una diversidad de concepciones de justicia social, pero cada una de ellas asume diferentes magnitudes. Identificamos tres etapas principales, en las cuales la noción de justicia se transforma en correspondencia con la descripción y explicación del orden social. Encontramos que en este cambio conceptual se manifiestan a nivel empírico las distintas fases de evolución del proceso de descentramiento, en el doble plano lógico y moral, investigado por la Escuela de Epistemología Genética de Jean Piaget (Figura n ${ }^{\circ}$ 10). 
FIGURA $N^{\circ} 10$

Etapas en la concepción de justicia social

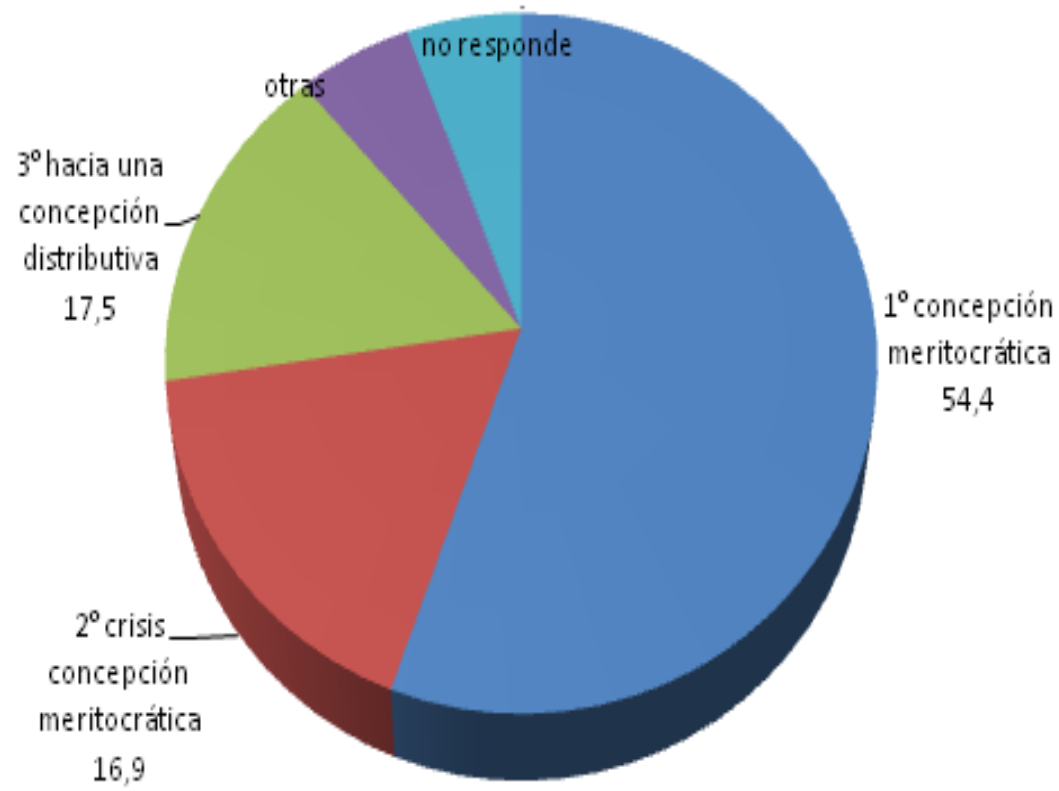

Fuente: Relevamiento propio en empresas (Solimeno, Argentina Frozen Fish, Angelito, Cabo Asturia, Cadelafi, Mardi). Diciembre 2014 y Julio 2015

En la primera etapa la concepción de justicia es claramente retributiva, centrada en la responsabilidad individual. Involucra al $54,4 \%$ de los entrevistados. Se evalúa el comportamiento meritorio o transgresor estrictamente en función dela conciencia e intencionalidad del agente. Es característica de sociedades complejas, funcionalmente interdependientes y de las etapas adultas de la psicogénesis en las que prima la interiorización moral subjetiva: el autocontrol emocional o auto coacción (Elías, 1989, p.449). Sin duda expresa una reestructuración evolutiva de la moral expiatoria de heteronomía pura, propia de sociedades primarias totémicas organizadas por solidaridad mecánica (Durkheim,1985) y de las etapas más infantiles del desarrollo, en las que prevalecen el control y sanción externos de la conducta, así como una noción de responsabilidad objetiva (por oposición a la subjetiva). Sin embargo, en una concepción retributiva de justicia, la dimensión social del comportamiento permanece inobservada o se presenta en segundo plano: el foco de atención se pone en la propia subjetividad. Concebir al individuo como agente plenamente responsable de la propia situación de vida es suponer que decide y actúa consciente, voluntaria e intencionalmente en todas las situaciones, independientemente de las acciones de otros sujetos, es decir, al margen de restricciones contextuales y circunstanciales. El énfasis puesto en la responsabilidad autocentrada implica una concepción atomizada del orden social, resultante de una simple agregación de individuos, escindible en unidades/acciones fragmentarias y desvinculadas unas de otras. Las relaciones son inobservadas.

En una segunda etapa se produce la crisis de la concepción de justicia social retributiva. El observable principal en ella es la no equivalencia entre el propio comportamiento y el sistema de premios y castigos. Involucra al 16,9\% de los entrevistados. Quienes expresan este tipo de juicio moral observan la contradicción: el buen comportamiento -el trabajo arduo, esfuerzo, productividad, etc.-ino siempre es premiado!, tal cual postula la justicia retributiva. Basta observar la fragilidad de las condiciones de vida de los trabajadores. 
En algunos casos, se menciona el propio comportamiento injustamente retribuido, o el deseo y necesidad subjetiva de mejorar (10,0\%). En otros casos, se pone el énfasis en el factor contextual que no retribuye con justicia $(6,9 \%)$ (Figura $n^{\circ} 11$ ).La toma de conciencia de esta contradicción perturba y desequilibra (Piaget, 1990) las convicciones morales exclusivamente centradas en el individuo. El nuevo observable-característico de esta segunda fase de construcción de la identidad moral sobre la falta de equivalencia entre el buen comportamiento del sujeto y la adversidad de las propias condiciones sociales de vida- pone en crisis el previo autocentramiento individual. Esta crisis opera como factor de perturbación del equilibrio moral anterior y es una condición necesaria para su reestructuración a un nuevo nivel de complejidad.

FIGURA N¹1

Crisis de la concepción meritocrática. Segunda etapa: dos tipos.

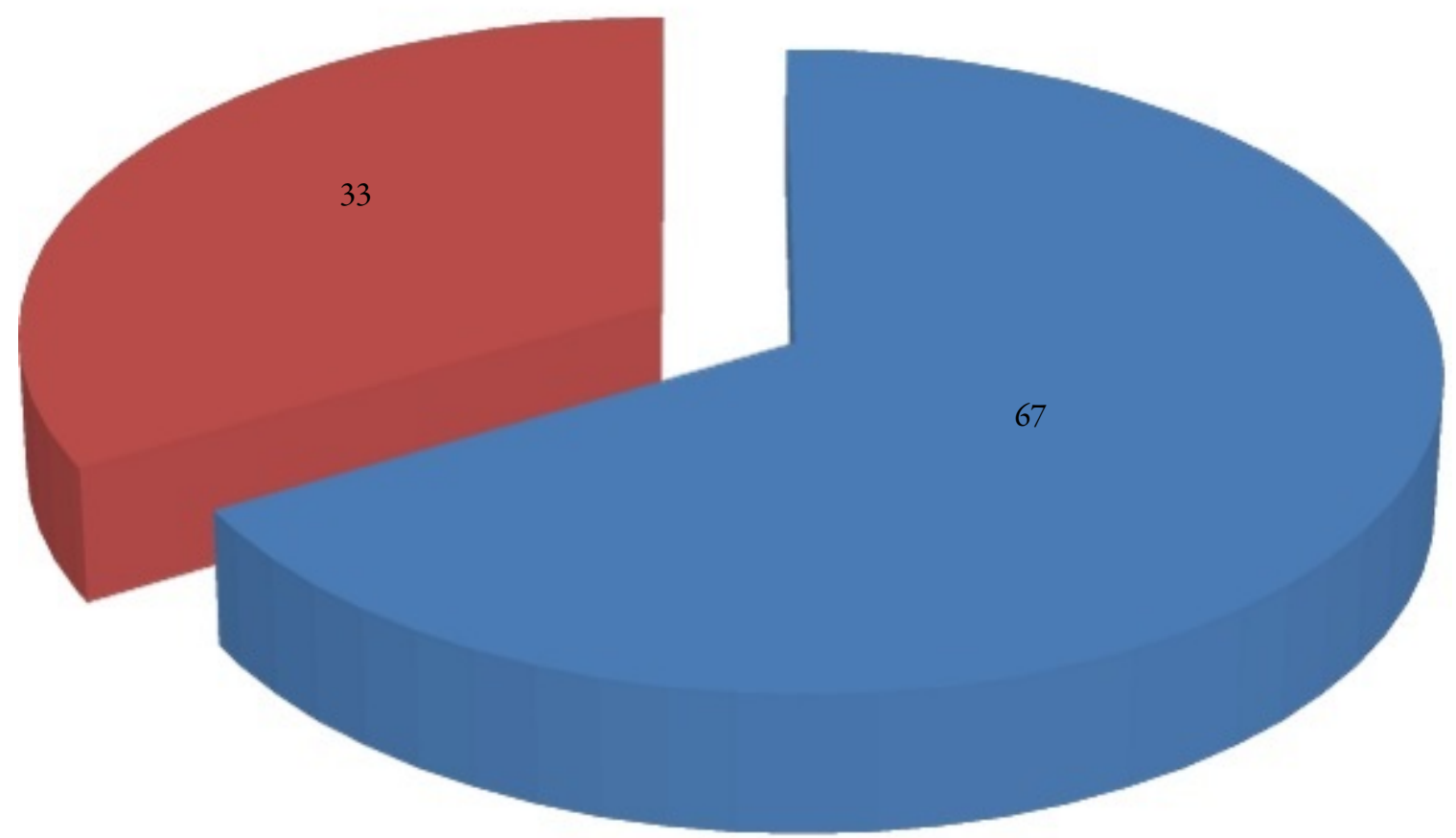

Fuente: Relevamiento propio en empresas (Solimeno, Argentina Frozen

Fish, Angelito, Cabo Asturia, Cadelafi, Mardi). Diciembre 2014 y Julio 2015

Una tercera etapa indica el origen -embrionario- de una concepción de justicia social distributiva. El observable principal en ella es el factor social. Involucra al 15,6\% de los entrevistados. Observar la dimensión social de la acción es observar el contexto de origen, las condiciones, circunstancias y restricciones según las cuales la acción propia siempre es limitada por la acción de los otros. Pero ¿qué es "la sociedad" para quienes observan el factor social? No sólo el observable de "lo social" es un punto de llegada, sino que se describe y explica de muy diversas maneras según el grado de conocimiento involucrado. En esta tercera etapa localizamos dos grupos (Figura ${ }^{\circ}{ }^{\circ}$ ). En el primero, más numeroso, la sociedad se concibe como una identidad total, "cosa" o entidad unívoca con características fijas, que se enfrenta al individuo -la "economía", los "políticos", el "gobierno"-, en vez de concebirse como un proceso dinámico configurado en acciones colectivas. La interacción observada a lo sumo se limita a un interaccionismo entre individuos. En el segundo grupo, minoritario, se registra la observación de relaciones -ya no entre individuos-, sino entre grupos sociales que constituyen clases: clases sociales. Esta es la precondición necesaria de un juicio moral de justicia distributiva. Juzgan su situación de vida en el marco de las restricciones impuestas a la acción individual por el grupo social de pertenencia. Y los comportamientos posibles para el grupo social de pertenencia se conciben como originados en correspondencia con las acciones y prácticas de los otros grupos humanos y/o clases 
de la estructura social. De este modo, es posible observar la existencia de agrupamientos en el orden social con sus relaciones intragrupales, intergrupales y transgrupales: relaciones entre acciones; relaciones entre relaciones, que originan estructuras; y relaciones entre estructuras, que originan sistemas (Piaget y García, 1989), integradas a nivel de la formación social de conjunto. Es esta la concepción propia de una etapa más compleja en el conocimiento de "lo social" 12 . Sólo el 5,6\% de los entrevistados se aproxima a una concepción moral de justicia distributiva. Si bien en ellos no se expresa aún con claridad una conceptualización "clasista", de interrelación entre clases sociales, se trata de trabajadores que ya juzgan su situación de vida observando las restricciones impuestas a la acción individual por la clase social de pertenencia. En algunos casos, establecen un vínculo entre su situación de clase y la situación de las clases acomodadas o privilegiadas del orden social ${ }^{13}$.

FIGURA No 12

Hacia una concepción de justicia social distributiva. Tercera etapa

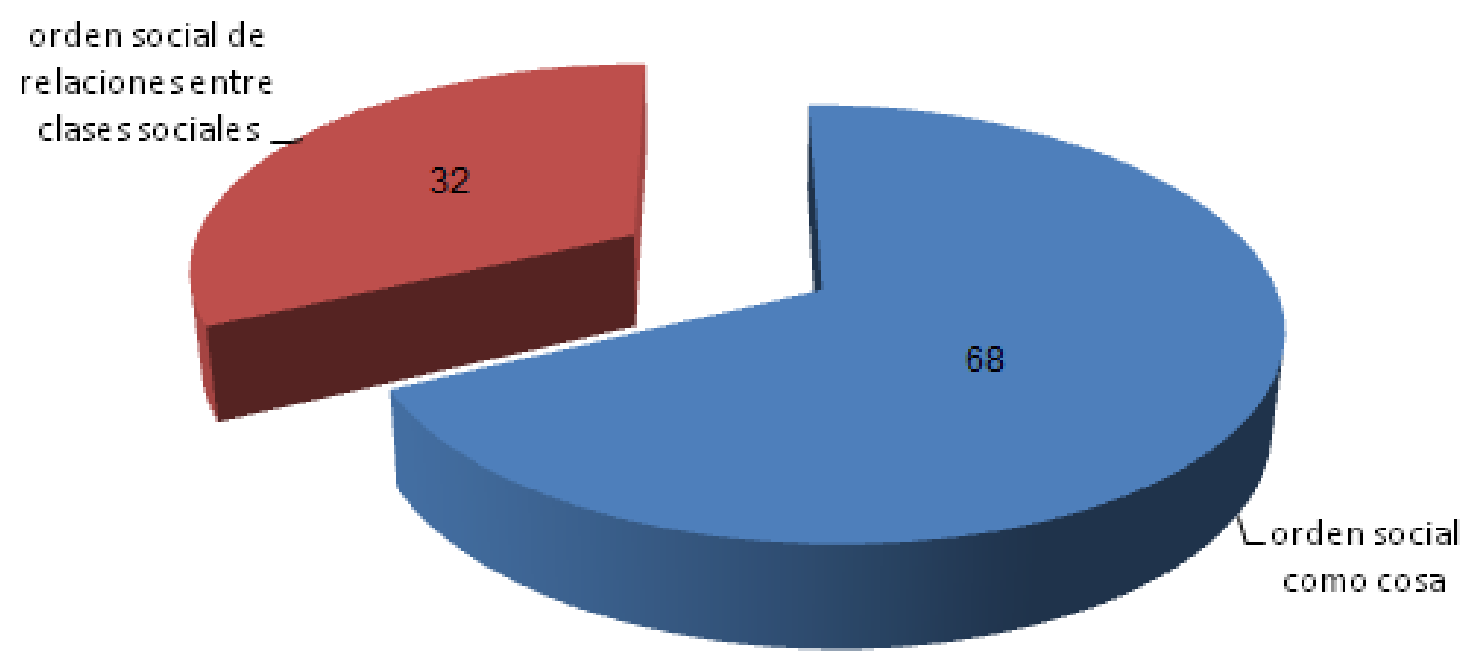

Fuente: Relevamiento propio en empresas (Solimeno, Argentina Frozen Fish, Angelito, Cabo Asturia, Cadelafi, Mardi). Diciembre 2014 y Julio 2015

Es posible preguntarse qué sucede con el conocimiento de lo social cuando se interroga explícitamente por la sociedad. Aquí cabe una advertencia de índole metodológica. Bien se podría objetar que la minoritaria atribución de responsabilidad a los factores sociales descripta anteriormente puede vincularse al tipo de preguntas formuladas en el relevamiento. La secuencia analizada interroga por la situación de vida del propio entrevistado. Deliberadamente los estímulos desencadenantes de su juicio morallo encierran en lo "individual", con la hipótesis de que sólo quien observare la incidencia de lo social en la configuración de las propias condiciones de vida logrará "sortear" la presión "unidireccional” de la pregunta. ¿Se incrementan los observables de "lo social" cuando se interroga explícitamente por la sociedad? A tal efecto, en la entrevista en terreno instalamos dos preguntas adicionales: 
92. ¿Ud. considera que la sociedad en Argentina es justa?

SI

NO

93. ¿Por qué la considera justa/ injusta?

Una amplia mayoría de entrevistados $(85,4 \%)$ considera a la sociedad argentina injusta. Todos ellos refieren a la "sociedad", pero lo social para ellos asume significados muy diversos. La gran mayoría (70\%) no menciona antagonismos de clase a la hora de describir la injusticia social. Un $24 \%$ hace referencia a un rasgo social negativo, como si la sociedad fuera una totalidad unívoca. Un $20 \%$ refiere a la falta de solidaridad y discriminación, sin mencionar identidades grupales o colectivas. Sólo un $30 \%$ refiere a la existencia de desigualdad entre clases sociales. Lo hace en términos dicotómicos. La mitad menciona a los empresarios o "los ricos versus el resto". La otra mitad se distribuye entre quienes distinguen entre los estratos más desfavorecidos-los desocupados, la gente en situación de calle, los pobres, etc.- y el resto de la sociedad, o bien entre la clase trabajadora y el resto. Por último, un grupo de menor peso (15\%), pero significativo para el análisis, indica la existencia de contradicciones y conflictos intra clase obrera. Estos entrevistados atribuyen la injusticia social a las diferencias internas de la clase trabajadora. Remarcan los antagonismos entre los trabajadores que se esfuerzan duro y los desocupados (inmigrantes en muchos casos) favorecidos por el Estado a través de subsidios, planes sociales de asistencia, o bien mencionan a los trabajadores que pagan ciertos impuestos (por ejemplo, a las ganancias) respecto de los que no. Es decir, en vez de focalizarse en las confrontaciones estructurantes del orden social, en los antagonismos de capital y la fuerza de trabajo, enfatizan en las divisiones internas entre las distintas fracciones de la clase trabajadora. En una palabra, a pesar de instalar en la entrevista la pregunta por lo "social" para evaluar criterios de justicia, no llegan al tercio los entrevistados que responden refiriendo a relaciones entre clases sociales en el seno del orden social (Figura $\left.\mathrm{n}^{\circ} 13\right)$.

FIGURA No 13

¿Por qué considera que Argentina es una sociedad injusta?

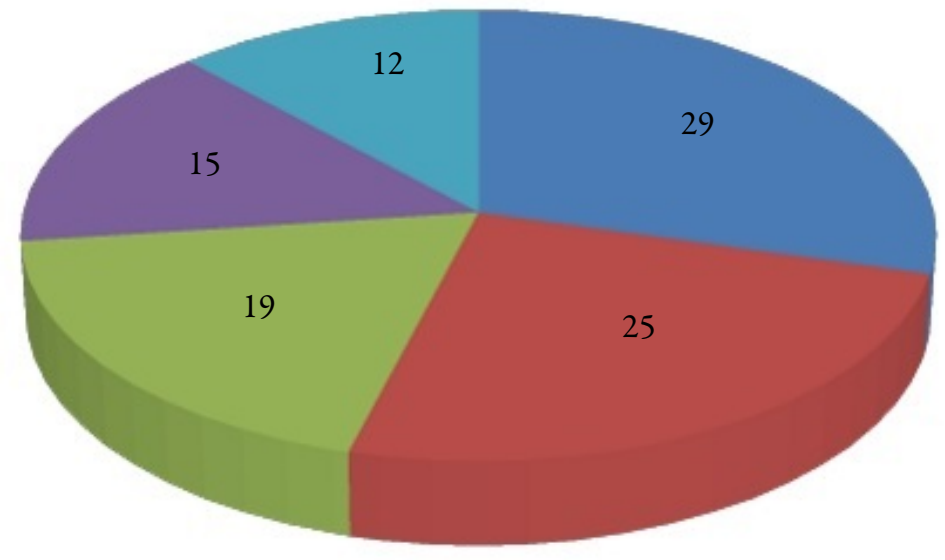

desigualdad entre clases sociales $(29,1 \%)$

arden social como totalidad $(24,6 \%)$

desigualdad entre individuos $(19,4 \%)$

conflicto intraclase trabajadora $(14,9 \%)$

no sabe/ no contesta/otra $(11,9 \%)$ 


\section{Conclusiones}

Consideramos que aun en su carácter exploratorio, y sin pretensiones de generalización al conjunto de los $t$ rabajadores de Argentina en la actualidad, nuestro estudio ofrece pistas valiosas para identificar, no sólo una e tapa dominante en la construcción de la conciencia moral sobre la justicia social, sino el papel inhibitorio que la misma ejerce en la construcción de conocimiento objetivo sobre el orden social. Aporta evidencia empírica significativa sobre la importancia en dicho proceso de la ruptura del autocentramiento, en el doble plano lógico y moral, lo cual se expresa en la crisis de una noción de responsabilidad estrictamente individual en la evaluación de las restricciones o condiciones positivas experimentadas en la propia situación social de vida. Esta ruptura es una precondición necesaria en la construcción del conocimiento de la pertenencia a una clase social, de la situación de clase en función de las relaciones objetivas que la clase de pertenencia establece con las otras clases de la estructura social, así como, finalmente, del conjunto de relaciones involucradas en funcionamiento sistémico del orden social.

El predominio de una moral de justicia retributiva meritocrática de responsabilidad estrictamente individual sin duda facilita la justificación de las políticas actualmente en curso, a pesar del deterioro progresivo en las condiciones sociales de vida de los trabajadores. Buena parte de los trabajadores entrevistados parece atribuir el bienestar adquirido en la primera década y media del siglo veintiuno exclusivamente a su esfuerzo individual, desestimando por completo el papel causal de los factores sociales en el avance del proceso de igualación. Lo social resulta inobservado: pareciera no darse la relevancia debida a las políticas socioeconómicas y culturales impulsadas precedentemente por el Estado, determinantes de las probabilidades objetivas de mejora de la situación personal.Esto pudo haber incidido en el triunfo electoral del actual gobierno. Sólo una minoría observa que el esfuerzo individuales una condición necesaria, pero no suficiente, para transformar una situación de vida adversa. El gran número de trabajadores sacrificados con condiciones de vida profundamente negativas pone en evidencia que el factor social es la variable causal o explicativa y el esfuerzo individual solamente un factor interviniente.

A partir de una concepción meritocrática se responsabiliza individualmente a los ocupados por sus bajos salarios, a los desocupados por sus despidos y a los pobres por su pobreza, en nombre de la falta de méritos suficientes o comportamientos virtuosos. Se los estigmatiza con acusaciones de pereza, baja productividad, ineficiencia, corrupción ${ }^{14}$, o bien se les endilga insuficiencia de aptitudes, habilidades y talentos. Al mismo tiempo, se promueve la falsa idea de que el trabajador disciplinado y obediente no corre riesgos sociales, lo cual divide a los trabajadores en "merecedores" y "no merecedores". En otras palabras, se piensa que "cada quien tiene lo que merece”, y si le va mal... “ipor algo será!”. Esta concepción ideológica, originada en el siglo dieciocho para confrontar la concepción aristocrático feudal precedente ${ }^{15}$, reaparece en la actualidad reforzada a través del sistema educativo formal y los medios de comunicación masivos.

El dominio de una moral de justicia retributiva meritocrática de responsabilidad individual opera como obstáculo epistemológico para observar las relaciones entre clases sociales. Es la imagen liberal típica de la sociedad de los individuos, que oculta la producción social de la pobreza, la relación existente entre el proceso de acumulación capitalista y la expropiación creciente de la fuerza de trabajo. A lo sumo se observa un interaccionismo individual correspondiente a lo social como totalidad cosificada, enfrentada al individuo.

La desigualdad social, para sobrevivir y sostenerse en el tiempo, requiere de la construcción de una ilusión (Freud, 1990), de una "irrealidad” (Romero, 1989): su resolución utópica en un futuro cronológicamente impreciso, que siempre corre hacia adelante, como la línea del horizonte. Como en las promesas de salvación de las grandes religiones universales, las estrategias del poder son expertas en el diferimiento de la dicha ${ }^{16}$. Casi un siglo antes de acuñarse el concepto de posverdad, como mentira que apela a las emociones e ignora los hechos, Sigmund Freud definió la ilusión como creencia propia de las etapas primarias del desarrollo dela afectividad. Una lógica que prescinde del principio de realidad en el análisis de la propia situación, con la simple finalidad de satisfacer las necesidades y deseos subjetivos. Establece relaciones de participación entre 
hechos y procesos objetivamente inconexos, para obtener los resultados subjetivamente esperados. Obviando la adecuación racional causal entre medios y fines, a través de la "omnipotencia del pensamiento", lo que realmente se desea, finalmente sucede.

La concepción de una justicia retributiva inmanente al orden social expresa el predominio de etapas primarias de la evolución moral y cognitiva. Fundada en la creencia, el razonamiento transductivo y una causalidad mágico-fenomenista expresa una lógica preconceptual subjetiva y singularmente motivada. Sin distinguir procesos objetivos de atribuciones subjetivas prescinde de cualquier tipo de verificación empírica socializable a partir de procedimientos regulados por las reglas cooperativas del pensamiento operatorio reversible, es decir, de una lógica racional hipotético-deductiva. No hay modo de demostrar objetivamente a nivel empírico la existencia de una justicia inmanente operante en el orden social, pues si bien un sinnúmero de comportamientos meritorios son premiados y otros tantos transgresoresson castigados, también hay un sinnúmero de comportamientos meritorios que no reciben nunca su correspondiente retribución y otras tantas faltas que jamás son castigadas. En el creyente en la justicia retributiva inmanente, estos hechos son anulados como observables: los desconoce, sin necesidad de explicación alguna

Pierre Rosanvallon (2012) explica la congruencia de la moral meritocrática en el ideario actual de una "igualdad de oportunidades y derechos", en el plano de la ciudadanía, el mercado, y, en última instancia, de la condición humana:

El efecto igualador de la circulación de las diferencias también procedió, de manera más duradera, de un impulso psicológico. Si el individuo se afirma como una libertad, la plenitud de su existencia se identifica con una capacidad de proyectarse en el tiempo, de no estar ya asignado a un sitio, encerrado en un estado determinado. En este sentido es como hay que comprender la expresión "igualdad imaginaria”. No corresponde tanto a la formación de una representación mental, a la evocación de un estado específico venidero, como al hecho de considerar abierta para sí la posibilidad de un cambio de situación. Es la idea de posibilidad, en su misma indeterminación lo que es esencial...Un mundo de semejantes se define en este marco como aquel el cual cada uno puede proyectarse en la condición de los otros, ya sea en el modo ventajoso de una mejoría de su suerte o en el modo pesimista del temor a encontrarse en una situación degradada (pp. 75 y 76).

El principio de una igualdad de oportunidades restringida al vértice de la sociedad fue aquí la máscara de la reproducción masiva de los lugares en el conjunto de la sociedad. Es exactamente el trabajo de la ideología vaciar la realidad de esta manera, enmascarada detrás de la ostentación de principios que nadie puede impugnar (p.140).

El sueño y la creencia en la posibilidad de ascenso social individual parecen prevalecer frente al deseo de cambio estructural de las condiciones objetivas de vida. La meritocracia del extremo superior define la igualdad como posibilidad teórica de ascender a la elite de todos los que tengan méritos suficientes.

La construcción de una ficción de sociedad de competencia generalizada, con reglas supuestamente iguales para todos, en las que intervienen el azar y el mérito, y en la que necesariamente hay ganadores y perdedores, consagra la jerarquización social de hecho. Aun eliminando las desigualdades sociales de origen persisten en este marco las del talento y capacidad. La idea de igualdad moral de la especie humana encubre la desigualdad material y naturaliza la jerarquización social preexistente.

Para finalizar, es posible preguntarse cuáles son los factores necesarios para superar una concepción meritocrática de justicia social. ¿Depende de las condiciones materiales de existencia? Hemos encontrado un incremento de la crisis de este tipo de concepción en los trabajadores con peores condiciones ocupacionales relativas (Tabla $\mathrm{n}^{\circ}$ 4). 
TABLA No 4

Factores de incremento de la crisis de la concepción meritocrática de justicia social

\begin{tabular}{|l|l|}
\hline $\begin{array}{l}\text { FACTORES DE INCREMENTO DE LA CRISIS DE } \\
\text { LA CONCEPCION MERTOCRATICA DE JUSTICIA SOCIAL }\end{array}$ & $\begin{array}{c}\text { DIFERENCIA } \\
\text { PORCENTUAL }\end{array}$ \\
\hline *Ocupados no calificados & $+22 \%$ \\
\hline * Jornada laboral extensiva ( más de ocho horas) & $+22 \%$ \\
\hline *Trabajadores informales o "en neg ro" ( sin \\
$\begin{array}{l}\text { vacaciones pagas, cobertura de salud, aguinaldo y } \\
\text { salario familiar) }\end{array}$ & $+18 \%$ \\
\hline * Trabajadores que buscan segunda ocupación & \\
\hline complementaria del salario principal & $+18 \%$ \\
\hline * Trabadores en seudocooperativas, sin convenios & $+12 \%$ \\
\hline colectivos de trabajo vigentes & \\
\hline * Inquilinos / Sin propiedad de automóvil & $+19 \% /+24 \%$ \\
\hline
\end{tabular}

Fuente: Relevamiento propio en empresas (Solimeno, Argentina Frozen Fish, Angelito, Cabo Asturia, Cadelafi, Mardi). Diciembre 2014 y Julio 2015

Sin embargo los datos nos muestran que una situación social adversa es una condición necesaria para observar la falacia de la justicia retributiva: contribuye a su crisis, pero no es un factor suficiente para superarla. La moral meritocrática todavía mantiene una magnitud muy considerable en los trabajadores con peores condiciones laborales relativas ( Tabla $^{\circ} 5$ ). 
TABLA N ${ }^{\circ} 5$

Magnitud (\%) de la concepción meritocrática en trabajadores con peores condiciones laborales relativas

\begin{tabular}{|l|l|}
\hline CARÁCTER SOCIOCUPACIONAL DE LOS TRABAJADORES & $\begin{array}{l}\text { CONCEPCION } \\
\text { MERITOCRTICA (\%) }\end{array}$ \\
\hline *Ocupados no calificadas & 50 \\
\hline * Jornada laboral extensiva & 47,5 \\
\hline $\begin{array}{l}\text { *Trabajadores informales/ "en negro" ( sin vacaciones } \\
\text { pagas, cobertura de salud, aguinaldo y salario familiar) }\end{array}$ & 48 \\
\hline $\begin{array}{l}\text { * Trabajadores que buscan segunda ocupación } \\
\text { complementaria del salario principal }\end{array}$ & 57 \\
\hline $\begin{array}{l}\text { * Trabadores en seudo cooperativas, sin convenios } \\
\text { colectivos de trabajo vigentes }\end{array}$ & 58 \\
\hline * Inquilinos ( no propietarios de casa)/ Sin auto & 45 \\
\hline
\end{tabular}

Fuente: Relevamiento propio en empresas (Solimeno, Argentina Frozen Fish, Angelito, Cabo Asturia, Cadelafi, Mardi). Diciembre 2014 y Julio 2015

Consideramos que otros factores-de carácter cultural, epistémico y emocional- podrían estar explicando su persistencia. Podemos mencionar la incidencia de menores niveles de educación formal alcanzados, de cosmovisiones sacralizadas y pensamiento mágico, de prevalencia de involucramiento en relaciones sociales asimétricas e identidades expiatorias, así como la percepción de emociones positivas frecuentes, en el incremento de la concepción de justicia retributiva inmanente (Tabla $\left.n^{\circ} 6\right)$.

\section{TABLA No 6}

Otros factores de incremento de la concepción meritocrática de justicia social

\section{IDENTIDAD CULTURAL / EPISTEMICA/ EMOCIONAL}

\section{DIFERENCIA}

PORCENTUAL

* Menor nivel de educación formal alcanzado

$35 \%+$

* Cosmovisiones sacralizadas y pensamiento mágico (personificación of

$20 \%+/ 30 \%+$

objetos/ proyección)

* Identidades expiatorias en relaciones sociales asimétricas (frecuente ejercicio de la confesión/ asistencia a ceremonias religiosas)

* Sentimientos frecuentes de felicidad y fortuna

Fuente: Relevamiento propio en universo de trabajadores devotos de San Cayetano, Área Metropolitana de Buenos Aires, 2010. 
En suma, la construcción de un conocimiento más complejo del orden social y el desarrollo de una conciencia moral de justicia distributiva requieren del avance del proceso de descentración. Para que este proceso se realice es necesario el desenvolvimiento de una práctica social basada en relaciones democráticas de paridad, reciprocidad y cooperación autónoma y participativa. Las relaciones asimétricas de constreñimiento-predominantes en las etapas infantiles del desarrollo, en las sociedades primarias y en sociedades con creciente desigualdad de clase-dan origen a identidades afectivas, epistémicas y morales cualitativamente diversas a las producidas por relaciones sociales de reciprocidad y cooperación entre pares, propias de la vida adulta y de sociedades complejas interdependientes organizadas democráticamente.

Desde Marx sabemos que la realización de la humanidad como especie, como totalidad, es todavía un proyecto irrealizado. ¿Cuál es el "piso" y el "techo" de desarrollo humano que estamos construyendo para todos nosotros en el nuevo milenio?

\section{REFERENCIAS}

Atucha, A., López, M.T. y Volpato, G. (1997). Producto Bruto Geográfico Partido de General Pueyrredón años 1993-1996 a precios corrientes y constantes. Mar del Plata: UNMdP-FCEyS.

Bachelard, G. (1987). La formación del espiritu cientifico. Psicoanálisis del conocimiento objetivo. México: Siglo Veintiuno Editores.

Colombo, G. (2009). De "clasistas" a "burócratas": el devenir de una "traición”. Acerca de la construcción moral del enemigo político en un sindicato de la industria del pescado (Mar del Plata - Argentina, 1997 - 2007). Revista Colombiana de Antropología, 47(1), 43-68.

Colombo, G., Nieto, A., y Mateo, J. (2010). Precarización y fraude laboral en la industria pesquera marplatense. El caso de las cooperativas de fileteado de pescado. Recuperado de http://www.trabajo.gba.gov.ar/informacion/masse/ca tegoriaA/13_MATEO_Precarizacion_y_fraude_laboral_en_la_industria_pesquera_marplatense.pdf

Durkheim, E. (1993). Las formas elementales de la vida religiosa. Madrid: Alianza Editorial.

Durkheim, E. (1985). La división del trabajo social. Barcelona: Planeta Agostini.

Elías, N. (1989). El proceso de la civilización. Estudios sociogenéticos y psicogenéticos. México: Fondo de Cultura Económica.

Gennero de Rearte, A., Graña, F., y Liseras, N. (2009). Industria manufacturera. Evolución reciente, situación actual y expectativas de las Pyme industriales. Informe 2008. Mar del Plata: UNMdP.

Mauss, M. (2009). Ensayo sobre el don. Forma y función del intercambio en las sociedades arcaicas. Buenos Aires: Katz Editores.

Monod, J. (2000). El azar y la necesidad, Ensayo sobre la filosofía natural de la biología moderna. Barcelona: Tusquets Editores.

Muleras, E., Schulze, M. S., Muñiz, M. B. y Azcarate, J. (2018) Conciencia moral y conciencia social en los trabajadores de la industria de procesamiento de pescado de la ciudad puerto de Mar del Plata, Argentina. En T. Pontón Aricha y M. Vázquez Fariñas (coord.), L. López Molina (dir.), Cádiz: del floreciente S. XVIII al port of thefuture del s.XXI. Madrid: Editorial Dykinson

Muleras, E., Forte, G., Hernández, M., Damiano, F., Biscione, G.,...Muñiz, B. (2016).La representación de lo real y su diversidad: la concepción del poder y la justicia en Argentina del siglo XXI. Revista de la Facultad de Ciencias Sociales, 92, 138-139. Recuperado de http://www.sociales.uba.ar/wp-content/blogs.dir/219/files/2016/11/24 -avances.pdf

Muleras, E. (2015a).Concepciones en pugna sobre justicia social en trabajadores de Argentina en el siglo veintiuno, Dossier Luchas ideológicas, batallas culturales y conflicto social. Conflicto Social, 8(14),195-220.

Muleras, E. (2015b). Las concepciones de la equidad y la justicia social en los trabajadores de la industria del pescado de la ciudad de Mar del Plata en lectura comparativa. Revista de Estudios Maritimos y Sociales, 7-8, 83-103. Recuperado de https://estudiosmaritimossociales.org/archivo/n7-8 
Muleras, E., Hernández, M., y Damiano, F. (2014). La representación de lo real y su diversidad: la concepción del poder y la justicia en Argentina del siglo XXI. Revista de la Facultad de Ciencias Sociales, 85,114-116.

Muleras, E. (2013). Sociogénesis de la identidad epistémica y moral de los trabajadores del Área Metropolitana de Buenos Aires. Hacia una pedagogía de la desobediencia a la inhumanidad del orden social: la construcción de una reflexión para la acción. En Anuario 2010/2011 del Instituto de Investigaciones de Ciencias de la Educación (pp. 611-623). Buenos Aires: Secretaría de Publicaciones de la Facultad de Filosofía y Letras, Universidad de Buenos Aires.

Muleras, E. (2012). Pedagogía de la desobediencia a la inhumanidad del orden social. La construcción de una reflexión para la acción. Saarbrücken: Editorial Académica Española (EAE) AV Akademikerverlag, GMBH\&Co.KG.

Muleras, E. (2011). Las precondiciones socioculturales del conocimiento popular del proceso de desaparición de personas durante la dictadura cívico militar (1976-1983). Conflicto Social, 4(6), 153-169. Recuperado de https: //publicaciones.sociales.uba.ar/index.php/CS/article/view/341/309

Muleras, E. (2011).Psicogénesis y Sociogénesis del conocimiento del orden social en un universo de trabajadores creyentes de Argentina: los devotos de San Cayetano. Educação e Fronteiras, 1(2), 98-117. Recuperado de http: //ojs.ufgd.edu.br/index.php/educacao/article/view/1453/862

Muleras, E. (2010). Poder, conocimiento y creencias religiosas en los trabajadores del siglo XXI. Cuadernos de Análisis Politico Nelson Gutiérrez, 3, 15-37.

Muleras, E.(2009). Sacralización y Desencantamiento: Hacia una sociogénesis del conocimiento del orden social. Revista del IICE, Facultad de Filosofía y Letras, UBA, 27,121-145.

Muleras, E. (2008). Sacralización y Desencantamiento. Las formas primarias del conocimiento del orden social. Buenos Aires: Miño y Dávila Editores.

Nieto, A., y Colombo, G. (2009). Lucha de calles en la industria de la pesca. Conflicto Social, 2(1), 168-194.

Nieto, A. (2010). Amotinados. Ira obrera en la industria pesquera argentina, 1997-2007. Revista Lavboratorio, 23, 95-135.

Piaget, J. (1990). La equilibración de las estructuras cognitivas. Problema Central del Desarrollo. Madrid: Siglo XXI Editores.

Piaget, J., y García, R. (1989). Psicogénesis e Historia de la Ciencia. México: Siglo XXI Editores.

Piaget, J. (1984a). El criterio moral en el niño. Barcelona: Ediciones Martínez Roca.

Piketty, T.(2014). El capital en el siglo veintiuno. Buenos Aires: Fondo de Cultura Económica.

Rosanvallon, P. (2012). La sociedad de iguales. Buenos Aires: Editorial Manantial.

OXFAM (2018). Briefing Report January 2018 “Rewarding work, not wealth”. Recuperado de http://www.celag.org/ resumen-informe-oxfam-2018-premiar-trabajo-no-la-riqueza

CEPAL (2009). Informe en base a Encuesta de Hogares en dieciocho paises. Recuperado de https://www.cepal.org/es/c omunicados/cepal-pese-avances-recientes-america-latina-sigue-siendo-la-region-mas-desigual-mundo

Basualdo, E., Arceo, N., González, M., y Mendizábal, N. (2011) Documento no 9 Centro de Investigación y Formación de la República Argentina, Central de Trabajadores Argentinos (CIFRA CTA).

\section{Notas}

1 Este trabajo fue presentado por su autora en el XIX ISA World Congress of Sociology, el 20 de julio de 2018 en Toronto, Canadá.

2 Según el OXFAM Report (2018) el 82\% del incremento de la riqueza mundial en el último año queda en las manos del $1 \%$ más rico de la población del planeta, en tanto el $50 \%$ de la población más pobre no recibe nada de la nueva riqueza producida. Asimismo se consigna que un total de 2.043 personas que poseen fortunas personales superiores al billón de dólares. La riqueza de estos multimillonarios ha crecido en un año 762 billones de dólares, un (monto que permitiría erradicar a nivel mundial siete veces la pobreza extrema. Entre los años 2006 y 2015 su riqueza se incrementa en un promedio anual del $13 \%$, mientras que los salarios de los trabajadores sólo crecen en promedio un $2 \%$. A su vez, el esfuerzo en el trabajo ya no necesariamente garantiza progreso para las clases trabajadoras: el informe indica que el 43 
\% de la población joven activa no tiene trabajo o, si trabaja, sus bajos ingresos no le permiten salir de la pobreza. Entre 1995 y 2014, en 91 países de un total de 135, el aumento de la productividad laboral no se acompaña de incrementos salariales. En la misma línea, la investigación de Thomas Piketty (2014) sobre la evolución histórica de la distribución de la riqueza durante los últimos tres siglos en más de veinte países, pone en evidencia el incremento de la concentración de capital en el siglo veintiuno. En el caso de EEUU - principal potencia económica mundial- el decil superior del ingreso nacional representa el 45/ 50\% de la población entre 1910 y 1920; se reduce a menos del 35\% de 1950 a 1970, y vuelve a incrementarse al 45/50\% entre 2000 a 2010 (gráfico $n^{\circ}$ 1, p. 39). En el caso de la relación entre capital e ingreso en Europa, el autor señala que el capital privado represente seis/ siete años de ingreso nacional en 1910; se reduce a dos/ tres años en 1950, para volver a incrementarse a cuatro/ seis en el año 2010 (gráfico no 2, p. 41).

3 Según una Encuesta de Hogares realizada en dieciocho países en el año 2009, los hogares más ricos - 10\% del total de hogares- perciben el $34 \%$ del ingreso nacional, en tanto los hogares más pobres $-40 \%$ del total de hogares- reciben el $15 \%$ del ingreso nacional.

4 Proyecto CONICET/ UBACYT (Universidad de Buenos Aires, Instituto de Investigaciones en Ciencias de la Educación e Instituto Gino Germani): "La representación de lo real y su diversidad. La concepción del poder y la justicia social en fracciones de trabajadores de Argentina en el siglo veintiuno”. Equipo de Investigación: Forte, Damiano, Hernández, Schulze, Muñiz, Azcárate y Biscione, con dirección de la autora.

5 Un sondeo internacional sobre las percepciones de la justicia social en doce países (Fundación Jean-Jaurès Francia; Brookings Institution, EEUU y Fundación Europea de Estudios progresistas), citado por Pierre Rosanvallon (2012), hace observable una mayoritaria tolerancia implícita a la desigualdad. Una encuesta del año 2009 sobre percepción de las desigualdades y sentimiento de justicia en Francia registra un 90\% de entrevistados que condenan la brecha de ingresos y proclaman la necesidad de satisfacer necesidades básicas. Sin embargo, una alta proporción - 57\%-considera necesaria esa brecha para promover el dinamismo económico. El porcentaje de aceptación de la desigualdad aumenta al 85\% de los entrevistados cuando se trata de remunerar "méritos" individuales diferentes.

6 El relevamiento en terreno fue realizado por un equipo integrado por un total de veinte personas entre investigadores, becarios y estudiantes de la Universidad Nacional de Mar del Plata y de la Universidad de Buenos Aires.

7 Quien da tiene poder, porque obliga a la retribución (Mauss, 2009).

8 Involucra respuestas del tipo: №1 :"Y porque uno hace y tiene lo que quiere" / No 36 "Porque todo lo que tengo es con esfuerzo" / No 56: "Me levanto todos los días a trabajar, trato de ser bueno, de cumplir"/ No 70: "Porque uno elige ser lo que es”. Fuente: Relevamiento propio en empresas (Solimeno, Argentina FrozenFish, Angelito, Cabo Asturia, Cadelafi, Mardi). Diciembre 2014 y Julio 2015.

9 Involucra respuestas del tipo: No54:"Siempre trabajé y merezco estar mejor"/ No25: "Porque siempre una persona que merece algo mejor con todo el sacrificio que hace" / No 31: "Porque en el otro trabajo me echaron sin causa/No32:"Nadie se lo merece. Porque todos necesitamos un sueldo digno. Trabajas todo el día. Estamos más horas acá adentro que con la familia”. Fuente: Relevamiento propio en empresas (Solimeno, Argentina FrozenFish, Angelito, Cabo Asturia, Cadelafi, Mardi). Diciembre 2014 y Julio 2015.

10 Involucra respuestas del tipo No 86: "Por falta de posibilidad de estudiar, tuve que salir a trabajar"/ No 63:"Porque ya termino la época de la esclavitud, acá estamos como esclavos”. Fuente: Relevamiento propio en empresas (Solimeno, Argentina FrozenFish, Angelito, Cabo Asturia, Cadelafi, Mardi). Diciembre 2014 y Julio 2015.

11 En los trabajadores creyentes entrevistados se incrementa la concepción de justicia retributiva inmanente, tanto individual como divina o trascendente. Entre los estudiantes universitarios de la Facultad de Ciencias Sociales de la UBA, pertenecientes en su mayoría a sectores medios de la Ciudad de Buenos Aires con mayor grado relativo de nivel formal educativo alcanzado, la atribución de responsabilidad por la propia situación de vida a factores de carácter social alcanza mayor magnitud relativa.

12 Es posible identificar esa progresión en la historia de la filosofía social y la sociología. La visión atomista propia de la filosofía iusnaturalista de los siglos XVII y XVIII;el planteo de la sociedad como totalidad indiferenciada y opuesta a la conciencia individual en la sociología científica de Durkheim, y la concepción más compleja, inaugurada por la sociología del comportamiento de Marx, que, finalmente permite distinguir los niveles de organización de la acción humana, del nivel atómico intracelular al de la formación social de conjunto.

13 No 72:"No merecido. Porque creo que todos nos merecemos vivir mejor nos rompemos la espalda, vivimos día a día, hay gente que le sobra"; No 99: "No merecido. Porque uno trata de hacer las cosas bien, los que no cumplen son ellos, quedé en la calle porque quebraron".

14 Se puede ver múltiples ejemplos en las declaraciones de altos funcionarios públicos en los medios de comunicación. Algunos a continuación:"Le hicieron creer a un empleado medio que su sueldo medio servía para comprar celulares, plasmas, autos, motos e irse al exterior. Eso fue una ilusión, eso no era normal" (Declaraciones del Presidente del Banco de la Nación Argentina, Radio La Red, Mayo 26, 2016). "Les hicieron creer que podrían vivir así eternamente" (Gabriela Michetti, Vicepresidente de Argentina, 5 de mayo de 2016 en https://www.pagina12.com.ar/diario/elpais/1-30063 4-2016-05-31.html). En el mismo sentido pueden analizarse las declaraciones del Presidente Macri del 13 de enero 
de 2016 sobre despidos en el Estado en https:/www.pagina12.com.ar/diario/elpais/1-290189-2016-01-13.html o las declaraciones del jefe de gobierno porteño sobre la represión a los maestros que reclamaban convocatoria a paritarias para fijar el salario docente en https://www.pagina12.com.ar/31156-la-justificacion-de-la-represion, 11 de abril 2017)

15 Ya se esboza en el artículo VI de la Declaración Francesa de los derechos del Hombre y del Ciudadano (1789/ 1793): "Todos los ciudadanos, siendo iguales a sus ojos [de la ley] son igualmente admisibles a todas las dignidades, puestos y empleos públicos, según su capacidad y sin otra distinción que la de sus virtudes y sus talentos"(La negrita es nuestra).

16 Sobre la promesa de reducción de la inflación y la pobreza a mediados del 2016, ver declaraciones de la Vicepresidenta de la Nación:"A partir del mes de julio, se va a notar sustancialmente la baja de la inflación, y, a partir de ahí, se dará una baja permanente". En https://www.pagina12.com.ar/diario/elpais/1-300634-2016-05-31.html. Sobre la posterior promesa de reducción de la inflación para el año 2019, ver declaraciones del Presidente de la Nación en http://www.la nacion.com.ar/2051719-mauricio-macri-insiste-el-dolar-no-es-un-problema-el-problema-es-la-inflacion. 